\title{
Molekularbiologische Untersuchungen zur Phylogenie der cheilanthoiden Farne (Pteridaceae-Cheilanthoideae) des südlichen Afrika
}

\author{
Wolf L. Eiserhardt
}

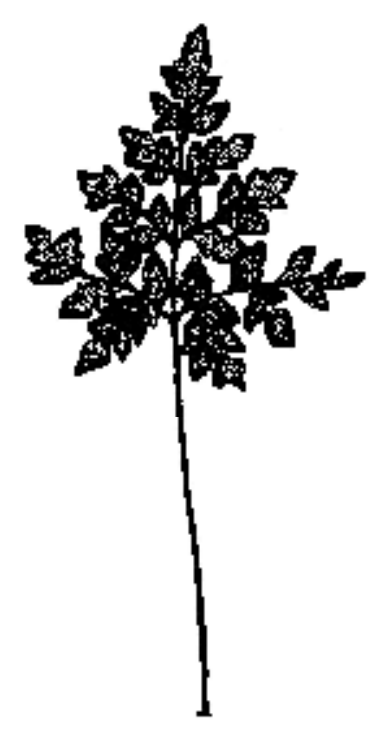

Staatsexamensarbeit im Fach Biologie

Universität Hamburg,

Biozentrum Klein Flottbek

und Botanischer Garten

Hamburg, 2007 
Molekularbiologische Untersuchungen zur Phylogenie der cheilanthoiden Farne (Pteridaceae-Cheilanthoideae) des südlichen Afrika

Wolf L. Eiserhardt

Staatsexamensarbeit im Fach Biologie

Gutachter: Prof. Dr. Jens G. Rohwer

Dr. Tassilo Feuerer

Abgabetermin: 20.12.2007

55 Seiten, 15 Abbildungen, 5 Tabellen.

Titelbild: Cheilanthes deltoidea, Zeichnung aus Burrows (1990:141). 


\section{Inhalt}

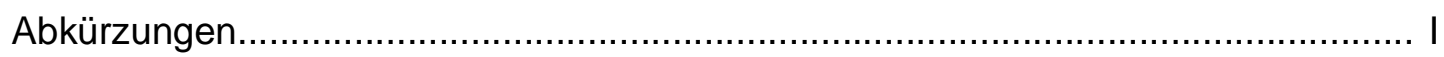

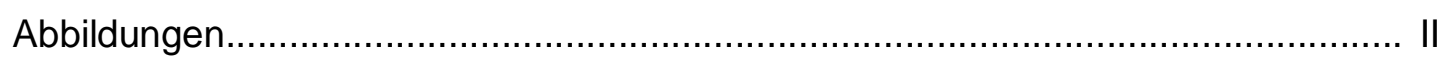

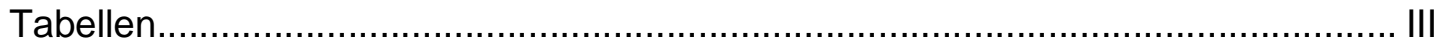

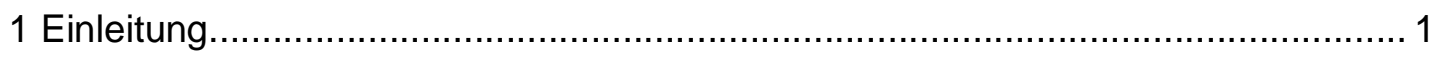

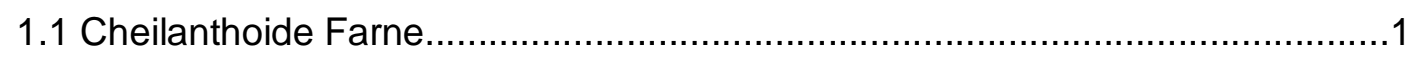

1.2 Taxonomie und Phylogenie .................................................................... 3

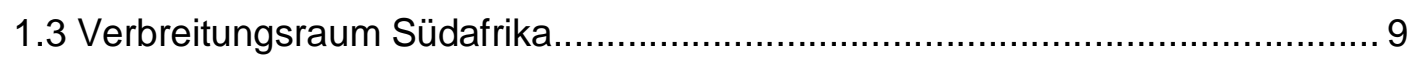

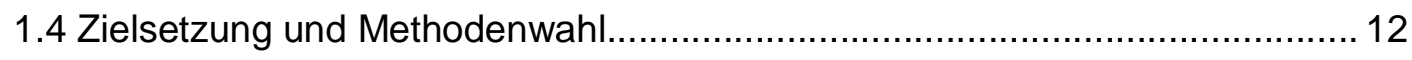

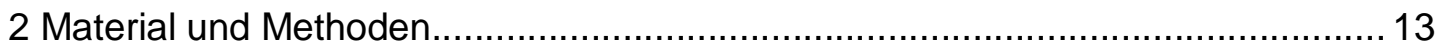

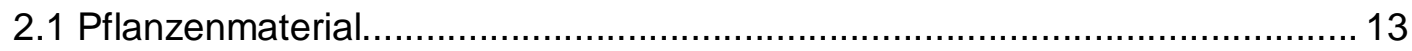

2.2 Bestimmung der DNA-Sequenzen.......................................................... 13

2.3 Erstellen der Datenmatrix („Alignment“) ................................................. 17

2.4 Phylogenie-Rekonstruktion............................................................. 17

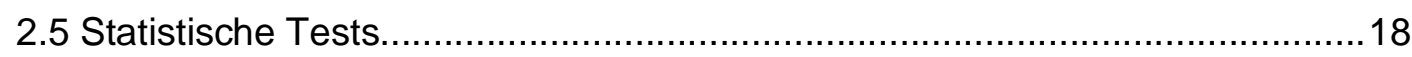

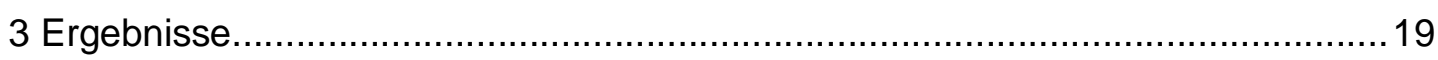

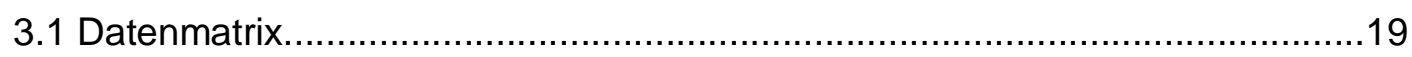

3.2 Phylogenetische Untersuchung ........................................................ 19

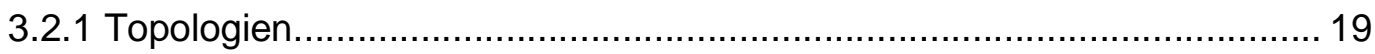

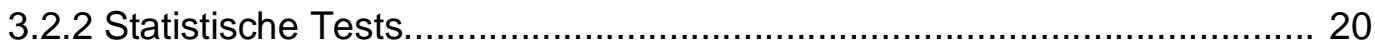

3.2.3 Position der neu untersuchten Spezies............................................... 20

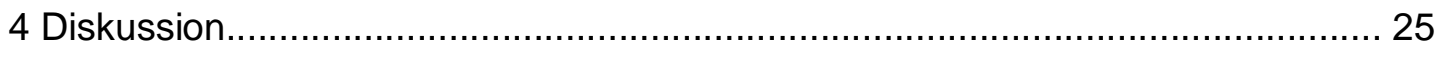

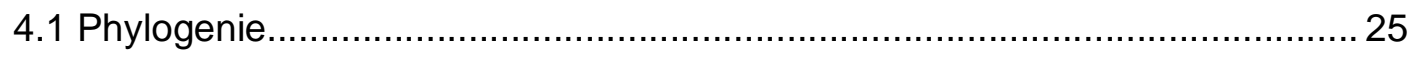

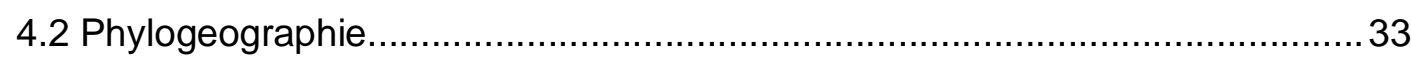

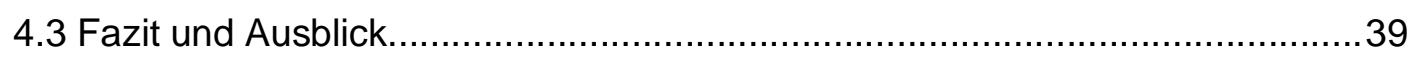

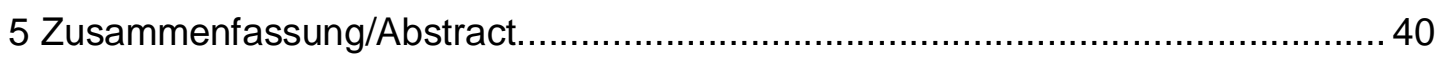

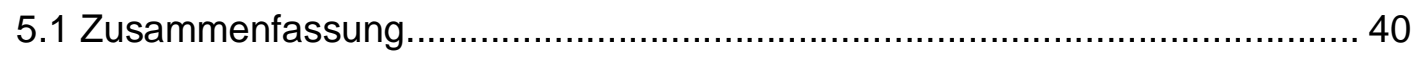

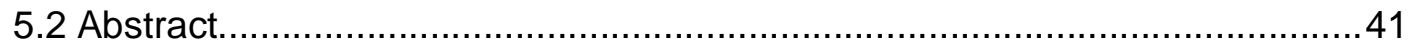

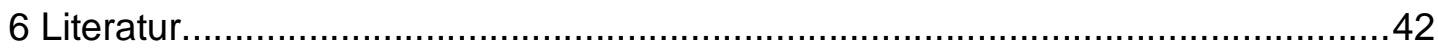

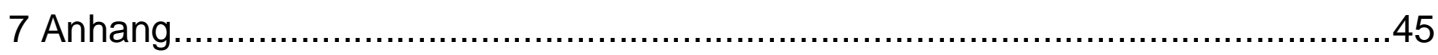

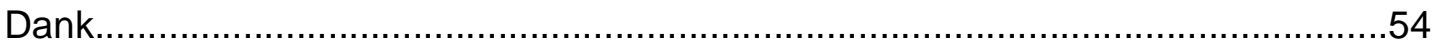

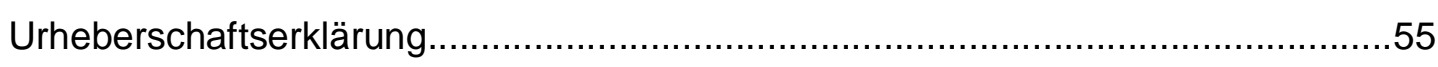




\section{Abkürzungen}

$\begin{array}{ll}\text { BPB+Glyc. } & \text { Bromphenolblau + Glycerin (vgl. Anhang Tab. 7.3) } \\ \text { BPP } & \text { Bayesian Posterior Probability (-Wert) } \\ \text { IGS } & \text { Intergenic Spacer } \\ \text { MCMC } & \text { Markov Chain Monte Carlo } \\ \text { ML } & \text { Maximum Likelihood } \\ \text { MLBS } & \text { Maximum Likelihood Bootstrap (-Wert) } \\ \text { MP } & \text { Maximum Parsimony } \\ \text { MPBS } & \text { Maximum Parsimony Bootstrap (-Wert) } \\ \text { TBE } & \text { Tris-Borsäure-EDTA (vgl. Anhang Tab. 7.3) }\end{array}$




\section{Abbildungen}

1.1 Cheilanthes rawsonii, Ch. deltoidea - Pflanzen am natürlichen Standort 2

1.2 Molekulare Phylogenie der Cheilanthoideae, zusammenfassend nach verschiedenen Autoren 5

1.3 Diversitätszentren der cheilanthoiden Farne 10

1.4 Vermutete phylogeographische Beziehungen der Cheilanthoideae des südlichen Afrika .....

2.1 Bindeposition der verwendeten „Primer“ im rbcL-Gen

3.1 Molekulare Phylogenie von 78 Arten der Cheilanthoideae, aus „Bayesian Inference" auf Basis von rbcL-Sequenzen, mit Unterstützungsklassen .23

3.2 Molekulare Phylogenie von 78 Arten der Cheilanthoideae, aus „Bayesian Inference" auf Basis von rbcL-Sequenzen, mit Herkunft der Proben

4.1 Cheilanthes multifida subsp. multifida, Ch. hastata-Pflanzen am natürlichen Standort

4.2 Cheilanthes robusta - Pflanze am natürlichen Standort und Habitat 30

4.3 Vereinigte Verbreitungsgebiete von Spezies 21-29 in Abb. 3.1

4.4 Verbreitungsgebiete von Cheilanthes contracta und Ch. parviloba 38

7.1 Herkunft des untersuchten Pflanzenmaterials .46

7.2 Molekulare Phylogenie von 79 Arten der Cheilanthoideae, aus heuristischer Suche (MP) auf Basis von rbcL-Sequenzen, mit „Bootstrap“-Werten 51

7.3 ML-„Bootstrap“ Consensus von 79 Arten der Cheilanthoideae, auf Basis von rbcL-Sequenzen, mit „Bootstrap“-Werten

7.4 Molekulare Phylogenie von 78 Arten der Cheilanthoideae, aus „Bayesian Inference“ auf Basis von rbcL-Sequenzen, mit „Posterior Probabilities“ 


\section{Tabellen}

1.1 Bei den Cheilanthoideae untersuchte DNA-Regionen / verwendete Methoden der Phylogenie-Rekonstruktion (verschiedene Autoren) …............................ 5

7.1 Herkunft und Belegnummern des untersuchten Pflanzenmaterials.................45

7.2 Verzeichnis der über die „GenBank“ bezogenen rbcL-Sequenzen .................47

7.3 Verwendete Chemikalien, „Kits“ und Lösungen ......................................... 49

7.4 Sequenzen und Quellen der verwendeten Oligonukleotide („Primer“)..............50 


\section{Einleitung}

\subsection{Cheilanthoide Farne}

Farne sind mehrheitlich Pflanzen der Tropen (Aldasoro et al. 2004, Tryon 1986), die ihre größte Diversität in Höhenlagen mit reichlich Regen und stabilen Temperaturen erreichen (Barrington 1993). In Trockengebieten würde man Farne nicht erwarten, dennoch begegnet man ihnen dort regelmäßig. Diese für Farne ungewöhnliche ökologische Präferenz ist in mehreren Familien unabhängig entstanden (vgl. Christ 1910:105 für eine Übersicht über „xerophytische“ Farne, Smith et al. 2006 für eine aktuelle Phylogenie). Die Stammesgeschichte der xerophytischen Farne ist insofern besonders interessant, als für ihre Entwicklung ganz andere Faktoren prägend gewesen sein müssen als bei den übrigen Farnen. Ihre gegenläufige ökologische Strategie lässt deutlich abweichende phylogenetische und phylogeographische Muster erwarten.

Die cheilanthoiden Farne (Pteridaceae-Cheilanthoideae) sind eine monophyletische Gruppe (Smith et al. 2006) von ca. 300 Arten. Diese Gruppe ist durch eine Präferenz für xerische Lebensräume charakterisiert (Schuettpelz et al. 2007:1180, Tryon \& Tryon 1973) und stellt oft ein signifikantes Element der Floren von ariden und semi-ariden Gebieten dar (Tryon et al. 1990). Tryon \& Tryon (1973) nennen für die Mehrheit der cheilanthoiden Farne felsige Standorte in Form von Vorsprüngen und Spalten in Klippen, Blockschutthalden, Hohlräumen am Fuß von großen Felsen und felsigem Boden (Abb. 1.1) als ökologische Ansprüche. Laut Tryon et al. (1990:231) sind die Wedel cheilanthoider Spezies häufig poikilohydrisch. Diese Strategie findet sich beispielsweise bei Cheilanthes marlothii (Hieron.) Schelpe aus dem südlichen Afrika (Burrows 1990). Eine andere verbreitete Strategie ist der Blattwurf, der z. B. bei den meisten in Namaqualand (Südafrika) endemischen Cheilanthes-Arten auftritt (Anthony 1984).

Einblicke in die Phylogenie der Cheilanthoideae können dazu beitragen, die Evolution von xerophytischen Farnen sowie allgemein die Reaktionen von Pflanzen auf veränderte Umweltbedingungen (Kirkpatrick 2007) besser zu verstehen.

\footnotetext{
Abb. 1.1 (Seite 2):

A, B: Cheilanthes rawsonii im Rosyntjieberg-Massiv, Richtersveld, Provinz Northern Cape, Republik Südafrika. Fotos: W. Eiserhardt, 09.10.2007.

C, D: Cheilanthes deltoidea in Umdaus, nördl. Namaqualand, Provinz Northern Cape, Republik Südafrika. Fotos: W. Eiserhardt, 28.08.2006.
} 

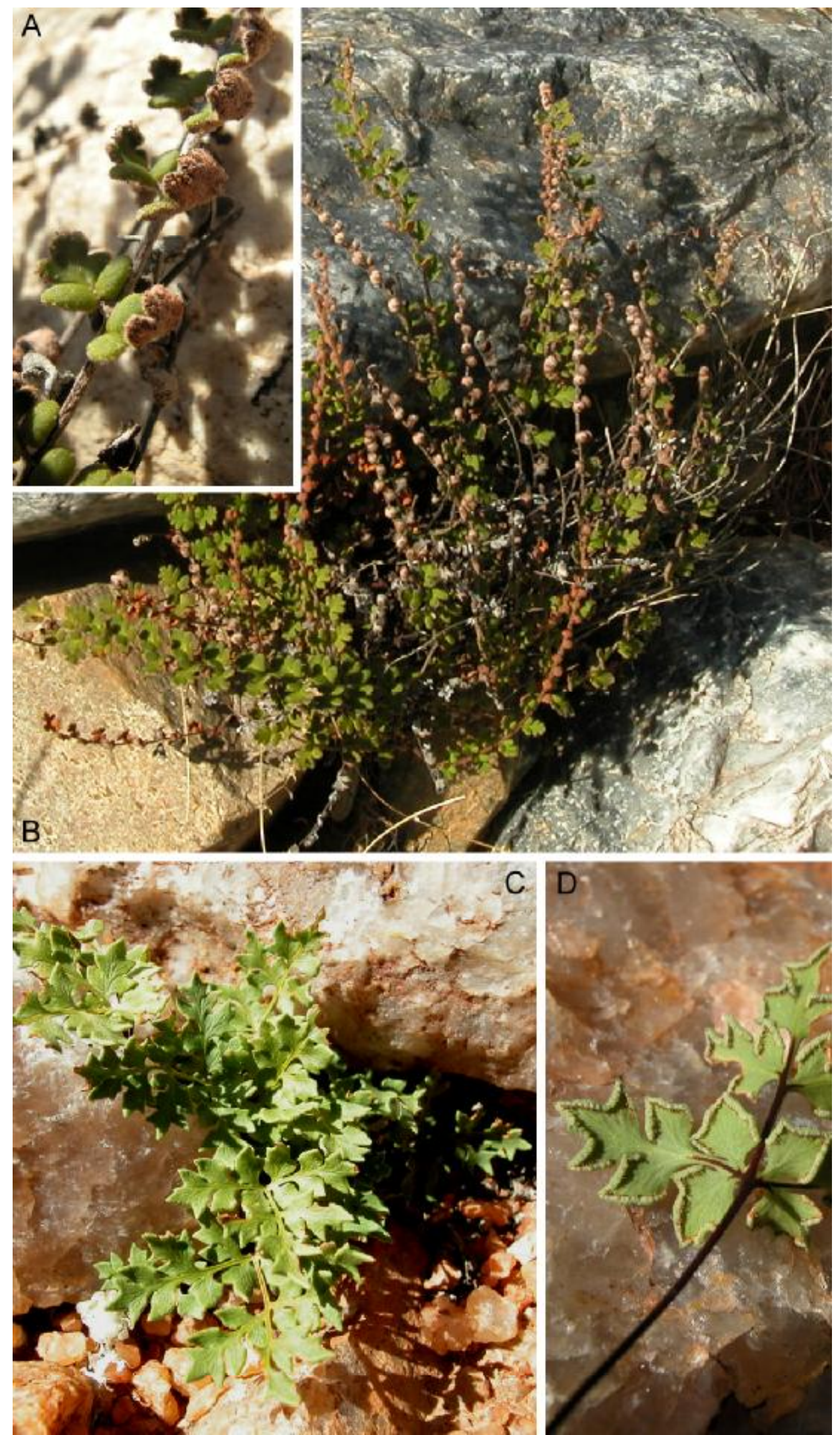


\subsection{Taxonomie und Phylogenie}

Nach dem gegenwärtigen Stand der phylogenetischen Systematik bilden die Farne eine monophyletische Gruppe mit den Schachtelhalmen und Gabelblattgewächsen, die als informelle Gruppe Moniliformopses („Monilophyten“) geführt wird (Smith et al. 2006). Diese ist die Schwestergruppe der Samenpflanzen. Die traditionell verwendete Gruppe „Farne und Farnverwandte“ ist nach heutigen Erkenntnissen nicht monophyletisch (Pryer et al. 2004, Smith et al. 2006). Innerhalb der Monilophyten bilden Smith et al. (2006) vier Klassen. Die cheilanthoiden Farne gehören zu der mit Abstand größten Klasse Polypodiopsida, den leptosporangiaten Farnen. Wesentliches synapomorphes Merkmal der Klasse ist das Leptosporangium mit einer aus einer einzelnen Zellschicht bestehenden Sporangienwand. Innerhalb der Polypodiopsida fallen die cheilanthoiden Farne in den basalen Teil der Ordnung Polypodiales. Sie sind Teil der Familie Pteridaceae, die ca. 950 Spezies in ca. 50 Gattungen umfasst.

Die vorliegende Untersuchung bezieht sich auf die informelle Untergruppe „Cheilanthoideae“ oder „Sinopteridaceae“ sensu Smith et al. (2006) der Pteridaceae. Diese Gruppe (im Weiteren: Cheilanthoideae i. e. S.) entspricht den Cheilanthoideae (J.Sm.) W.-C.Shieh sensu Tryon et al. (1990) ohne Cryptogramma R.Brown, Coniogramme Fée, Llavea Lagasca und Cosentinia Tod.. Letztere Taxa wurden aufgrund molekularer Ergebnisse (Zhang et al. 2005, Nakazato \& Gastony 2003) aus den Cheilanthoideae ausgeschlossen. Morphologische Synapomorphien für die nach Ausschluss dieser Gattungen verbliebene Gruppe sind noch nicht beschrieben worden.

Innerhalb der Cheilanthoideae sind natürliche Gruppen auf Basis nichtmolekularer Merkmale schwer zu finden (Tryon et al. 1990). Als Hauptproblem gilt konvergente Anpassung an Trockenheit (Tryon \& Tryon 1973), aber auch Alloploidie (Hybridisierung) und Aussterben werden als Gründe genannt (Tryon et al. 1990). Einen Überblick über die verschiedenen morphologischen, anatomischen, palynologischen, zytologischen, chemotaxonomischen und biogeographischen Bearbeitungen bieten Gastony \& Rollo (1995), Tryon \& Tryon (1982) und Anthony (1984).

Erst mit DNA-Sequenzen stand eine Datenquelle zur Verfügung, die von der konvergenten Anpassung an aride Lebensräume unbeeinflusst ist (Gastony \& Rollo 1995). Die erste molekularbiologische Untersuchung der Gruppe (Gastony \& Rollo 1995) ergab eine gut aufgelöste und gut unterstützte Phylogeniehypothese. Die Arten der Gattungen Cheilanthes Sw., Pellaea Link und Notholaena R. Br. sensu Tryon et al. (1990) bildeten darin jeweils keine Monophyla. Die Umgrenzungen 
anderer Taxa wurden durch das Ergebnis unterstützt, wie z. B. bei Argyrochosma (J.Sm.) Windham, einer Abspaltung von Notholaena. Daraus, dass für die bestätigten Taxa eine stabile Definition auf Basis morphologischer Merkmale verfügbar war, schlossen die Autoren auf eine generelle Vertrauenswürdigkeit der rbcL-Phylogenie. In der Folge wurden DNA-Sequenzen von weiteren Arten der Cheilanthoideae i. e. S. untersucht (Gastony \& Rollo 1998, Zhang et al. 2005, Prado et al. 2007, Zhang et al. 2007, Kirkpatrick 2007, Schuettpelz et al. 2007). Einige der Autoren (Gastony \& Rollo 1998, Zhang et al. 2007) folgten geographischen Kriterien für die Auswahl der untersuchten Arten, andere taxonomischen (Zhang et al. 2005, Kirkpatrick 2007). Das Methodenspektrum wurde sowohl bezüglich der untersuchten Sequenzregionen als auch bezüglich der Phylogenie-Rekonstruktion erweitert (Tab. 1.1). Auch Arbeiten zur Phylogenie der Pteridaceae insgesamt leisteten mit neuen Sequenzen, Auswertungsmethoden und Argumenten einen wesentlichen Beitrag (Prado et al. 2007, Schuettpelz et al. 2007). Die molekularen Ergebnisse sind untereinander weitgehend kompatibel. Die resultierende Phylogeniehypothese (Abb. 1.2) widerspricht in wesentlichen Punkten der jüngsten nichtmolekularen Revision der Unterfamilie (Tryon et al. 1990), bestätigt aber einige Taxa, die dort nicht anerkannt wurden und zeigt überdies bislang unbeschriebene Gruppierungen.

Bezogen auf die Gattungen sensu Tryon et al. (1990) lässt sich die Ergebnisslage bisheriger molekularer Untersuchungen folgendermaßen darstellen:

Cheilanthes Swartz: Die Gattung Cheilanthes sensu Tryon et al. (1990) teilt sich den molekularen Ergebnissen zufolge in zwei große und viele kleinere Gruppen bzw. einzelne Arten auf. Die beiden großen Monophyla sind allen Untersuchungen zufolge entfernt verwandt. Das eine Monophylum besteht aus neuweltlichen Spezies, die vordem verschiedenen Untergattungen und Sektionen von Cheilanthes oder dem Genus Mildella zugeordnet wurden. Diese Gruppe wurde von Gastony \& Rollo (1998:138) als „southwestern“ Cheilanthes diskutiert.

Das zweite große Monophylum wird von asiatischen Cheilanthes-Arten gebildet (Zhang et al. 2007). Dazu gehören auch die Gattungen Leptolepidium Wu, Sinopteris C.Chr. \& Ching, Cheilosoria Trev. und Aleuritopteris Fée sowie die asiatischen Spezies von Mildella Trev.. Die Eigenständigkeit dieser Gattungen (alle sind Abspaltungen von Cheilanthes) wird durch das molekulare Ergebnis nicht gestützt. Zhang et al. (2007) attestierten dem Clade eine starke morphologische Zusammengehörigkeit und vermuteten einen relativ jungen Ursprung. Drei 
Tab. 1.1: Bei den Cheilanthoideae untersuchte DNA-Regionen und verwendete Methoden der Phylogenie-Rekonstruktion (verschiedene Autoren).

\begin{tabular}{|c|c|c|c|c|c|c|c|c|c|c|}
\hline & \multicolumn{7}{|c|}{ untersuchte DNA-Regionen } & \multicolumn{3}{|c|}{ Phylogenie-Rekonstruktion } \\
\hline & $r b c \mathrm{~L}$ & ITS & $\begin{array}{c}r n \mathrm{~L} \\
\mathrm{~F}\end{array}$ & rps4 & $\begin{array}{c}\text { rps4- } \\
\text { trns }\end{array}$ & atpA & atpB & $\begin{array}{l}\text { Maximum } \\
\text { Parsimony }\end{array}$ & $\begin{array}{l}\text { Maximum } \\
\text { Likelihood }\end{array}$ & $\begin{array}{l}\text { Bayesian } \\
\text { Inference }\end{array}$ \\
\hline Gastony \& Rollo (1995) & $\mathrm{x}$ & & & & & & & $\mathrm{x}$ & & \\
\hline Gastony \& Rollo (1998) & $\mathrm{x}$ & $\mathrm{x}$ & & & & & & $\mathrm{x}$ & & \\
\hline Zhang et al. (2005) & $x$ & & & & & & & $x$ & & \\
\hline Zhang et al. (2007) & $x$ & & $\mathrm{x}$ & & & & & $x$ & & $\mathrm{x}$ \\
\hline Kirkpatrick (2007) & & & $x$ & $\mathrm{x}$ & $x$ & & & $x$ & $x$ & \\
\hline Prado et al. (2007) & $x$ & & & & & & & $x$ & & $x$ \\
\hline Schuettpelz et al. (2007) & $\mathrm{x}$ & & & & & $\mathrm{x}$ & $\mathrm{x}$ & & $\mathrm{x}$ & $\mathrm{x}$ \\
\hline
\end{tabular}

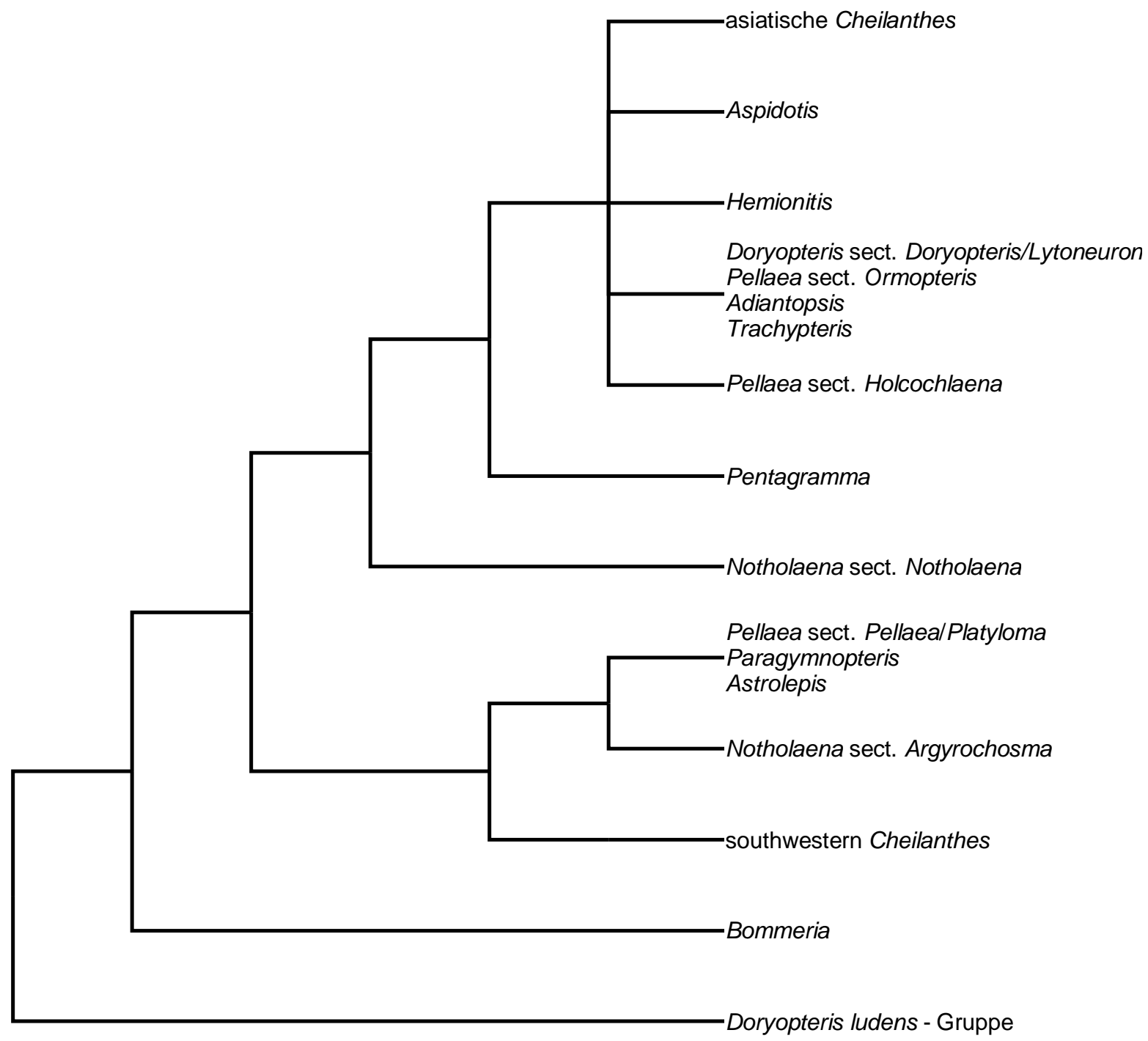

Abb. 1.2: Phylogeniehypothese für die Cheilanthoideae sensu Smith et al. (2006), zusammengefasst aus den molekularen Untersuchungen von Gastony \& Rollo (1995/98), Zhang et al. (2005), Zhang et al. (2007), Kirkpatrick (2007), Prado et al. (2007) und Schuettpelz et al. (2007). Die Benennungen sind informell und an den jeweils dominanten Taxa bzw. etablierten informellen Namen orientiert. Die Clades enthalten z. T. weitere Spezies, die traditionell anderen Genera als den hier genannten zugeordnet wurden (siehe Text). 
Cheilanthes-Arten sensu Tryon et al. (1990) stehen in den molekularen Phylogenien an der Basis von Notholaena sect. Notholaena (Gastony \& Rollo 1998).

Eine weitere Gruppe von Cheilanthes-Spezies bildet einen gemeinsamen Clade mit Doryopteris sect. Doryopteris/Lytoneuron, Pellaea sect. Ormopteris, Adiantopsis und Trachypteris (Prado et al. 2007, Kirkpatrick 2007).

Einige Spezies bilden schließlich bei Kirkpatrick (2007) einen Clade, dessen Krongruppe zur Gattung Aspidotis (Nuttall ex Hooker) Copel. gehört (ebenfalls eine Abspaltung von Cheilanthes, die von Tryon et al. 1990 nicht anerkannt wird). Die Integrität dieser Gattung wird dadurch bestätigt und ihre Separierung von den anderen Cheilanthes-Gruppen unterstützt. Aspidotis ist in allen anderen Analysen nur durch $A$. californica Nutt. vertreten. Diese Art zeigt stets eine unsichere Positionierung an der Basis des asiatischen Cheilanthes-Clade. Bei Kirkpatrick (2007) ist der asiatische Cheilanthes-Clade nicht vertreten, sodass die Verwandtschaft von Aspidotis unklar bleibt.

Notholaena R. Br.: Notholaena sect. Argyrochosma, auch als separates Genus Argyrochosma (J.Sm.) Windham beschrieben, ist den molekularen Ergebnissen zufolge eine natürliche Gruppe (Gastony \& Rollo 1998, Schuettpelz et al. 2007). Notholaena sect. Notholaena sensu Tryon et al. (1990) ist nach diesen Ergebnissen ebenfalls monophyletisch und gruppiert mit einigen neuweltlichen CheilanthesSpezies. Die Zusammenfassung der beiden Sektionen in eine gemeinsame Gattung Notholaena bestätigt sich nicht. Vielmehr dürfte Argyrochosma als Gattung Bestand haben (Gastony \& Rollo 1998).

Pellaea Link: Von vier für die Gattung Pellaea beschriebenen Sektionen (Tryon et al. 1990) zeigt sich molekular nur Pellaea sect. Platyloma (J.Sm.) Hooker \& Baker durchgehend als monophyletisch (Kirkpatrick 2007). Sie gruppiert dabei inmitten von Pellaea sect. Pellaea Link, die demzufolge paraphyletisch ist. Ebenfalls in Pellaea sect. Pellaea fallen alle bislang untersuchten Spezies der Gattungen Paraceterach Copel. und Paragymnopteris Shing (diese beiden Gattungen überschneiden sich in ihrer Artzusammensetzung weitgehend) sowie Astrolepis D.M.Benham. Paragymnopteris zeigt sich dabei als polyphyletisch. Der gemeinsame Clade aus Pellaea sect. Pellaea und Platyloma, Paragymnopteris, Paraceterach sowie Astrolepis ist durch die zytologische Synapomorphie $1 \mathrm{n}=29$ Chromosomen gestützt (Gastony \& Rollo 1998, Kirkpatrick 2007). Für eine taxonomische Gliederung innerhalb des Clade schlug Kirkpatrick (2007) eine Vierteilung in Pellaea, Platyloma, Astrolepis und Paragymnopteris vor. 
Pellaea sect. Ormopteris (J.Sm.) R.M.Tryon \& A.F.Tryon zeigt sich bei Kirkpatrick (2007) als paraphyletisch in einem Clade mit Doryopteris-Spezies. Bei Prado et al. (2007) resultiert sie monophyletisch, fällt aber zentral in die Gattung Doryopteris. Pellaea sect. Holcochlaena Hook. \& Baker zerfällt in drei Gruppen, die mit den anderen Sektionen nur entfernt verwandt sind. Bei Kirkpatrick (2007) bilden fünf der sechs untersuchten Spezies ein gut unterstütztes Monophylum. Die sechste, Pellaea calomelanos Link aus dem südlichen Afrika, gruppiert mit drei südafrikanischen Cheilanthes-Arten in der Verwandtschaft von Doryopteris sect. Doryopteris. Pellaea boivinii gruppiert mit den Arten der Gattung Hemionitis (Gastony \& Rollo 1995/98, Schuettpelz et al. 2007).

Doryopteris J. Sm.: Wie bei Schuettpelz et al. (2007) und Zhang et al. (2007) diskutiert, zerfällt Doryopteris in einen Teil um D. ludens, der möglicherweise die Schwestergruppe der übrigen Cheilanthoideae i. e. S. ist, und einen mehr abgeleiteten Teil um die Typspezies Doryopteris palmata (Willd.) J. Sm.. Letzterer Teil ist nach den Ergebnissen von Prado et al. (2007) paraphyletisch, da ein Clade von vier Spezies aus Pellaea sect. Ormopteris hinein gruppiert. Dadurch werden die Doryopteris-Spezies auf zwei Clades verteilt, und zwar entsprechend den Sektionen Doryopteris und Lytoneuron. Doryopteris sect. Lytoneuron gruppiert dabei eng mit Pellaea sect. Ormopteris. Doryopteris concolor (Langsd. \& Fisch.) Kuhn \& v.Deck. und Cheilanthes decora (Brack.) R.M.Tryon \& A.Tryon, die von verschiedenen Autoren entweder als Teil von Doryopteris oder von Cheilanthes behandelt wurden, gehören nach den molekularen Ergebnissen zu Doryopteris sect. Doryopteris.

An der Basis der Gruppe aus Doryopteris und Pellaea sect. Ormopteris stehen in den meisten Analysen die Gattungen Adiantopsis und Trachypteris sowie Arten von Pellaea sect. Holcochlaena und Cheilanthes.

Adiantopsis Fée: Adiantopsis bildet nach den Analysen von Prado et al. (2007) und Schuettpelz et al. (2007) eine Verwandtschaftsgruppe mit dem Doryopteris/Ormopteris-Komplex (s.o.) und Trachypteris. Die Monophylie der Gattung Adiantopsis wird durch die molekularen Analysen nicht in Frage gestellt (Prado et al. 2007).

Paraceterach (F.v.Mueller) Copel.: Die Gattung Paraceterach (F. v. Mueller) Copel. überschneidet sich weitgehend mit Paragymnopteris Shing (vgl. Kirkpatrick 2007:509). Die einzige molekular untersuchte Art von Paraceterach, die nicht auch 
unter Paragymnopteris geführt wird ( $P$. muelleri), gruppiert bei Kirkpatrick (2007) ebenfalls in die Verwandtschaft von Paragymnopteris.

Hemionitis L.: Die Monophylie der Gattung Hemionitis L., ohne Hemionitis elegans Davenp., wird durch die molekularen Ergebnisse gestützt. Bei Schuettpelz et al. (2007) bildet Hemionitis einen Clade mit Parahemionitis arifolia (Burm.f.) Panigrahi und Pellaea boivinii Hk. Letztere Spezies gehört traditionell zu Pellaea sect. Holcochlaena sensu Tryon et al. (1990) (s.o.).

Bommeria Fournier: Die Gattung Bommeria resultiert, unter Einbeziehung von Hemionitis elegans Davenp. als Bommeria elegans (Davenp.) Ranker \& Haufler, als monophyletisch (Gastony \& Rollo 1998). Sie bildet den basalsten Clade in den Cheilanthoideae i. e. S., abgesehen vom Doryopteris ludens-Clade.

Trachypteris Christ: Von der Gattung Trachypteris ist bislang nur die Spezies $T$. pinnata (Hook.f.) C.Chr. aus Südamerika/Galápagos molekular untersucht worden. Diese gruppiert in den molekularen Ergebnissen eng mit dem Doryopteris/ Ormopteris-Komplex (s.o.) und Adiantopsis (s.o.).

Pentagramma Yatsk., Windham \& E.Wollenw.: Pentagramma ist eine Abspaltung der traditionell taenitidoiden Gattung Pityrogramma Link. Den Ergebnissen von Gastony \& Rollo (1998) zufolge gehört Pentagramma zu den Cheilanthoideae i. e. S..

Formale Beschreibungen neuer Taxa innerhalb der Cheilanthoideae sind auf Basis der molekularen Ergebnisse noch nicht erfolgt. Die Auflösung und Unterstützung der bisher gefundenen Phylogeniehypothesen reicht nicht aus, um eine Neuordnung entgegen der traditionellen Taxonomie vorzunehmen. Außerdem ist bislang nur ein zu geringer Teil der Spezies molekular untersucht worden. Es gibt auch erst wenige Ansätze (Gastony \& Yastkievych 2001, Kirkpatrick 2007), die molekular aufgefundenen Gruppen mit gemeinsamen nichtmolekularen Merkmalen nachzuvollziehen. 


\subsection{Verbreitungsraum Südafrika}

Die Cheilanthoideae sind subkosmopolitisch verbreitet, mit der größten Diversität in Nord- und Südamerika nahe den Wendekreisen (Tryon et al. 1990). Tryon \& Tryon (1973) beschrieben weltweit sechs Diversitätsschwerpunkte: Mexiko, Brasilien, die Anden, Süd- und Ostafrika, China/Himalaya und Australien (Abb. 1.3). Diese Schwerpunktregionen sind bezüglich der vorkommenden Arten weitgehend disjunkt. Der Anteil gemeinsamer Spezies beträgt durchschnittlich nur 6,5\%, maximal 15\% zwischen den Anden und Brasilien. Eine besonders deutliche Trennung zeigt sich zwischen den neuweltlichen und den altweltlichen Vorkommen. 99\% der in der Neuen Welt vorkommenden Arten sind neuwelt-endemisch (Tryon \& Tryon 1973). Von den sechs Diversitätszentren der Cheilanthoideae sind vier, nämlich die drei neuweltlichen und Asien, in molekularen Phylogenien mit zahlreichen Spezies vertreten. Afrikanische und australische Arten sind bisher kaum molekular untersucht worden.

In Süd- und Ostafrika/Madagaskar kommen nach Tryon \& Tryon (1973) 58 Arten cheilanthoider Farne vor (Abb. 1.4). Anthony (1984) beschrieb 37 Arten für das südliche Afrika (Republik Südafrika, Lesotho, Swaziland, Namibia, Botsuana).

Innerhalb der Cheilanthoideae des südlichen Afrika fand Anthony (1984) im Rahmen einer biogeographischen Untersuchung eine Zweiteilung. Der eine Teil, bestehend aus 17 Spezies mit Verbreitungsschwerpunkt im Westen, Südwesten und Süden, wurde als „southwestern endemic element" bezeichnet. Diese Spezies sind mehrheitlich endemisch für das südliche Afrika und viele von innen haben ein sehr kleines Verbreitungsgebiet („restricted endemism“). Die Spezies mit Hauptverbreitung im östlichen Teil des südlichen Afrika haben nach Anthony größere Verbreitungsgebiete und sind „hauptsächlich tropisch“. Sie wurden in Abgrenzung zu den südwestlichen Arten als „eastern temperate and tropical element" beschrieben. Wegen seiner vielen kleinräumig endemischen Spezies wurde das „southwestern endemic element" von Anthony auf eine Speziation innerhalb seines heutigen Verbreitungsgebiets zurückgeführt: „One could therefore say that the southwestern corner of Africa has been a centre of cheilanthoid fern speciation" (Anthony 1984:278). Dies deckt sich mit der Vermutung von Tryon \& Tryon (1973), dass phylogenetische Beziehungen vor allem innerhalb der geographischen Schwerpunktregionen gesucht werden sollten (Tryon \& Tryon 1973:152). Diese Vorstellung, dass Abstammungsgemeinschaften innerhalb der Cheilanthoideae i. e. S. häufig eine zusammenhängende geographische Verbreitung haben, hat sich durch die heute verfügbaren molekularen Ergebnisse bestätigt (s. o.). 


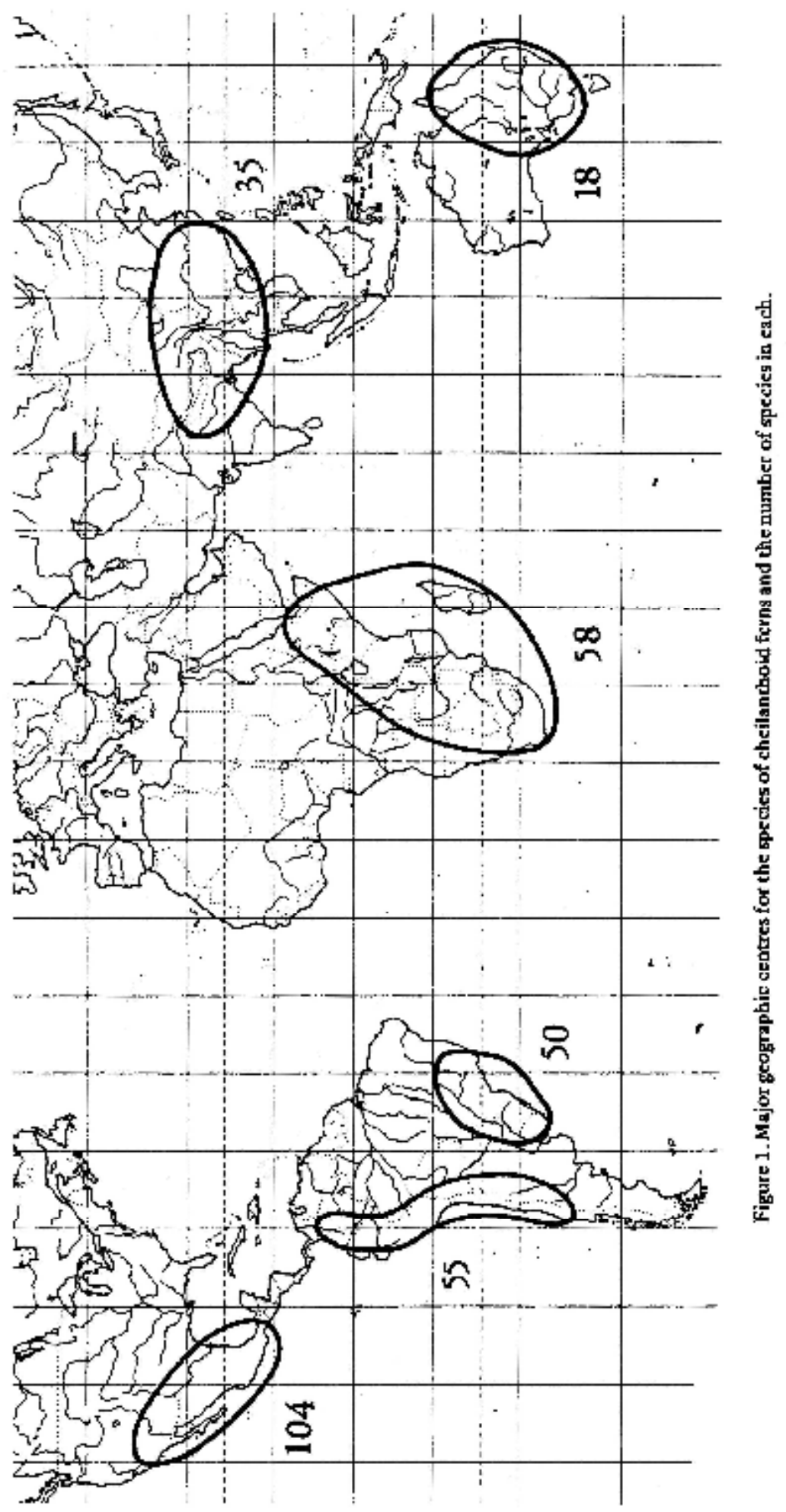

Abb. 1.3: Diversitätszentren der cheilanthoiden Farne. Unverändert aus Tryon \& Tryon (1973:147). 
Andererseits haben Moran \& Smith (2001) große morphologische Ähnlichkeiten zwischen einigen südafrikanischen und bestimmten neuweltlichen Cheilanthoideae festgestellt. Davon betroffen sind vier Spezies, die nach Anthony (1984) dem „southwestern endemic element“ angehören. Es ist auffällig, dass die afrikanischneuweltlichen Speziespaare sich nach der Beschreibung von Moran \& Smith z. T. stärker ähneln als die Spezies des „southwestern endemic element“ untereinander. Obwohl Konvergenz innerhalb der Cheilanthoideae immer eine nahe liegende Erklärung ist, könnte man vermuten, dass nicht nur einmalig, sondern sogar mehrfach ein Austausch zwischen Südafrika und der Neuen Welt stattgefunden hat.

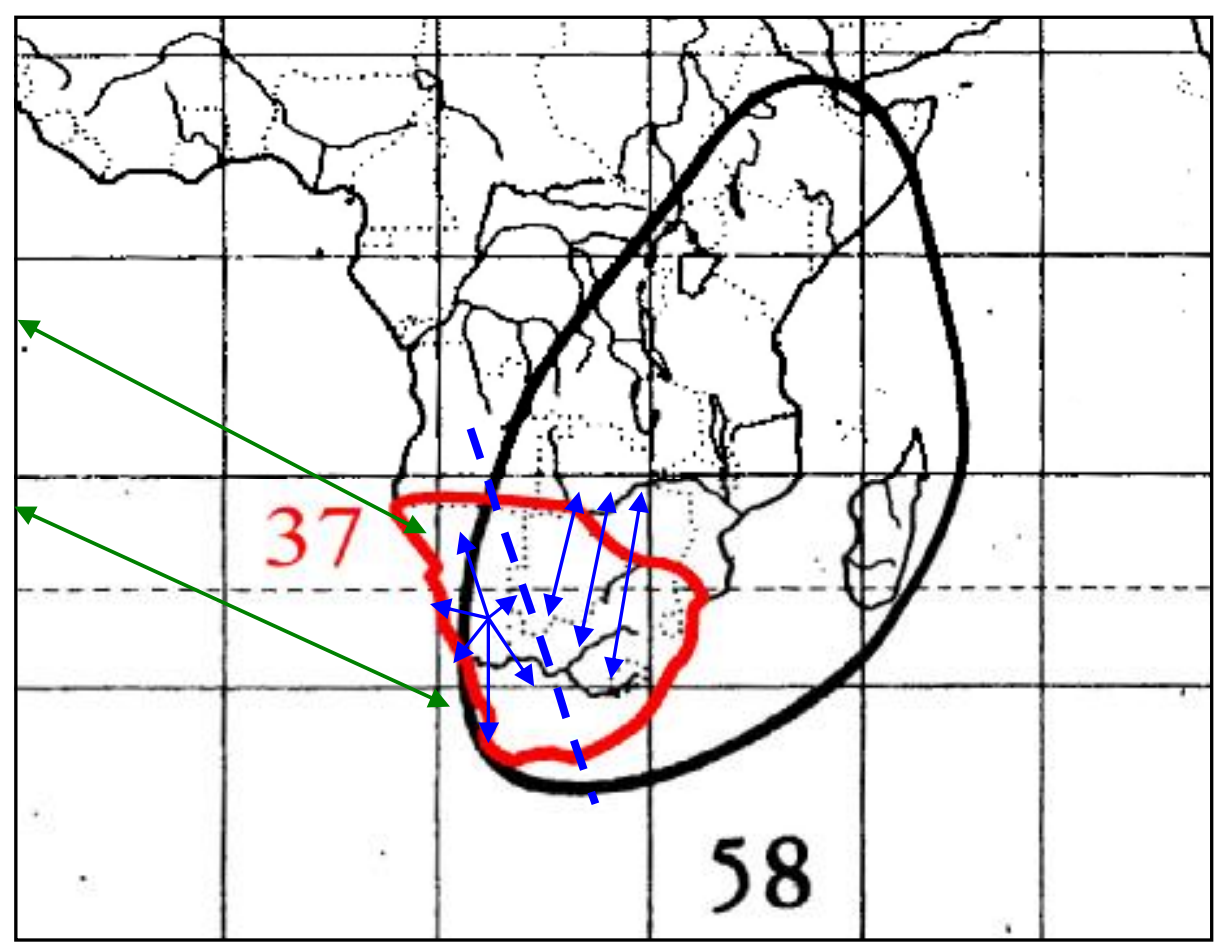

Abb. 1.4: Vermutete phylogeographische Beziehungen der Cheilanthoideae des südlichen Afrika. Schwarze Linie: Diversitätszentrum nach Tryon \& Tryon 1973 mit Artenzahl. Rote Linie: Untersuchungsgebiet von Anthony (1984) mit Artenzahl. BLAU: phylogeographische Beziehungen nach Anthony (1984) GRÜN: nach Moran \& Smith (2001). Grafik aus Tryon \& Tryon (1973), modifiziert.

Die bisherigen molekularen Ergebnisse zeigen, dass immer wieder Abstammungslinien der Cheilanthoideae die Region gewechselt haben. Austausch zwischen Kontinenten ist demzufolge nicht selten gewesen. Nach Kirkpatrick (2007) ist dies durch Langstreckenausbreitung von Farnsporen zu erklären. Langstreckenausbreitung ist bei Farnen insgesamt ein häufiger Prozess (Moran \& Smith 2001, Barrington 1993, Tryon 1986) und wurde auch von Moran \& Smith (2001) zur Erklärung der von ihnen beschriebenen Speziespaare vorgeschlagen. Nach Barrington (1993) spielen regionale Speziation und überregionaler Austausch für die Diversität von Endemismus-Zentren gleichermaßen eine Rolle. 
Eine molekulare Phylogenie könnte zeigen, welchen Anteil regionale Speziation und welchen Anteil Einwanderung an der heutigen Diversität der Cheilanthoideae im südlichen Afrika hat.

\subsection{Zielsetzung und Methodenwahl}

Von 14 Arten aus dem südlichen Afrika stand extrahierbares Material zur Verfügung. 11 davon sind bislang molekular nicht untersucht worden. Wie bei den meisten bisherigen molekularen Untersuchungen (vgl. Tab. 1.1) sollen Sequenzen des rbcLGens verwendet werden. Die "GenBank“ (NIH, Maryland) enthält eine große Zahl von rbcL-Sequenzen cheilanthoider Farne. Für keine andere DNA-Region sind vergleichbar viele Sequenzen vorhanden, sodass sich rbcL für eine Einordnung neuer Arten in eine globale Gesamtphylogenie anbietet. Außerdem gilt rbcL als Quelle vertrauenswürdiger molekularer Phylogenien innerhalb der cheilanthoiden Farne (Gastony \& Rollo 1998:143). Einige Autoren (Schuettpelz et al. 2007) meinen zwar, dass rbcL allein innerhalb der Cheilanthoideae keine ausreichende Unterstützung liefert, andererseits gibt es aktuelle Untersuchungen der Gruppe (Prado et al. 2007), die ausschließlich mit rbcL-Sequenzen arbeiten. Um erste Hinweise auf die phylogenetische Position von Arten zu erhalten, erscheint die Untersuchung von rbcLSequenzen jedenfalls als geeignetes Werkzeug. Eine Bearbeitung von weiteren Sequenzregionen war im Rahmen dieser Arbeit aus zeitlichen und finanziellen Gründen nicht möglich.

Der rbcL-Datensatz soll mit verschiedenen Methoden der Phylogenie-Rekonstruktion untersucht werden, um eine verbesserte Hypothese für die phylogenetische Position der südafrikanischen Arten zu erhalten. Als "traditionelles“ (Holder \& Lewis 2003) Standardverfahren soll „Maximum Parsimony“ angewendet werden. Zum Vergleich soll eine „Bayesian Inference of Phylogeny“ durchgeführt werden. Nach Yang (1996) erzielt „Maximum Parsimony“ bei Sequenzen mit variabler Substitutionsrate schlechtere Ergebnisse als bei konstanten Raten. Um der Struktur des Gens möglichst gerecht zu werden, kann bei „Bayesian Inference“ überdies ein Codon-Modell (Muse \& Gaut 1994, Goldman \& Yang 1994) angenommen werden. Vor dem Hintergrund dieser Ergebnisse soll diskutiert werden, welchen Anteil an der Diversität der untersuchten Arten a) der Austausch mit anderen Schwerpunktregionen und b) Speziation innerhalb der Region gehabt haben könnte. 


\section{Material und Methoden}

\subsection{Pflanzenmaterial}

Der größte Teil des untersuchten Pflanzenmaterials wurde vom Verfasser in der Republik Südafrika (Provinzen Northern Cape und Western Cape) im August/September 2006 gesammelt. Mit einem handelsüblichen GPS-Gerät (Garmin etrex) wurden für jede Aufsammlung die geographischen Koordinaten bestimmt. Teile von Sporophyten (in jedem Fall Wedel, wenn möglich auch Rhizomstücke) wurden gesammelt und gepresst. Teilweise wurden zusätzlich Wedelstücke auf Silicagel getrocknet. Von Koos Roux (Kapstadt) wurden zwei Aufsammlungen aus Südafrika, von Matthias Schultz (Hamburg) und Dirk Wesuls (Hamburg) drei Aufsammlungen aus Namibia freundlicherweise zur Verfügung gestellt. Des Weiteren wurde eine Aufsammlung von Teneriffa (Kanarische Inseln) zur Erweiterung des Datenbestandes bearbeitet.

Die Bestimmung der Arten erfolgte anhand der Herbarbelege unter Zuhilfenahme von Standortdaten (Ort, Höhe, Vegetationstyp, Mikrohabitat) und Fotografien der lebenden Pflanze. Bestimmt wurde mit dem Schlüssel von Burrows (1990), die Ergebnisse wurden mit den Beschreibungen von Burrows (1990) und Anthony (1884) abgeglichen. Zudem wurden Belege aus dem Herbarium Hamburgense (Universität Hamburg) und dem Compton Herbarium (South African National Biodiversity Institute, Kirstenbosch, Kapstadt) zum Vergleich herangezogen.

Für die molekularbiologische Untersuchung wurde von jeder gesammelten Spezies ein möglichst typisches Exemplar ausgewählt. Eine Untersuchung sämtlicher Exemplare war aus finanziellen Gründen nicht möglich. Eine Liste der Aufsammlungen, die in dieser Untersuchung verwendet wurden, findet sich in Tab. 7.1. Die Fundorte sind in Abb. 7.1 dargestellt.

\subsection{Bestimmung der DNA-Sequenzen}

\section{Labormaterial}

Eine Liste der verwendeten Chemikalien findet sich im Anhang (Tab. 7.3). Alle hitzestabilen Lösungen und Gebrauchsgegenstände wurden für 20 min bei $121^{\circ} \mathrm{C}$ und $2 \cdot 10^{5} \mathrm{~Pa}$ sterilisiert. Die verwendeten Chemikalien hatten den Reinheitsgrad „pro analysis". 


\section{Extraktion der DNA}

Zur Extraktion der DNA wurde das kommerzielle Invisorb Spin Plant Mini Kit (Invitek, Berlin) verwendet. Vorbereitend wurde das Pflanzenmaterial mit einer Schwingmühle (Retsch, Haan bei Düsseldorf) mechanisch zerkleinert. Dafür wurde von jedem Herbarbeleg, oder vorzugsweise von der zugehörigen Silicagel-getrockneten Probe, ca. 0,25 cm² Blattmaterial abpräpariert. Das abgenommene Material wurde zusammen mit zwei bis drei Stahlkugeln (ca. $3 \mathrm{~mm} \quad \varnothing$ ) in ein $2 \mathrm{ml}$-Reaktionsgefäß gegeben. Die Gefäße wurden, zusammen mit dem Einspannrahmen der Schwingmühle, von außen gründlich mit Flüssig- $\mathrm{N}_{2}$ durchgefroren und noch tief ausgekühlt für $30 \mathrm{~s}$ mit $50 \mathrm{~Hz}$ vibriert. Auf die zerkleinerten, noch kalten Proben wurde unverzüglich Lysispuffer und Proteinase K des „Kit“ gegeben. In Abweichung von der Gebrauchsanweisung des „Kit“ wurden 4 l Proteinase je Probe verwendet (Rohwer \& Rudolph, unpubl.) und die Lysis-Zeit auf eine Stunde ausgedehnt $(\mathrm{H}$. Schneider pers. Mitt.). Um Bruchstücke des Pflanzenmaterials aus dem Lysat zu entfernen, wurde dieses zunächst durch ein „Spin-Filter" aus dem „Kit“ zentrifugiert, welches danach verworfen wurde (Rohwer \& Rudolph, unpubl.). Die weiteren Schritte der Extraktion erfolgten anhand der Gebrauchsanweisung. Die Extrakte wurden bis zur weiteren Verarbeitung bei $4^{\circ} \mathrm{C}$ gelagert. Die Stahlkugeln wurden mit Ethanol gewaschen, für 20 min bei $121^{\circ} \mathrm{C}$ und $2 \cdot 10^{5} \mathrm{~Pa}$ sterilisiert und wieder verwendet.

Um den Erfolg der Extraktion zu überprüfen, wurde eine Gelelektrophorese mit anschließender Ethidiumbromid-Färbung durchgeführt. Dazu wurden $2 \mu$ jedes DNAExtraktes in einem Agarosegel (0,8\% Agarose in 0,5x TBE) aufgetrennt. Als Laufpuffer wurde 0,5x TBE, als Ladepuffer pro Probe $2 \mu \mathrm{BPB}+\mathrm{Glyc}$. verwendet. Die Gelelektrophorese wurde $45 \mathrm{~min}$ lang mit einer Spannung von $70 \mathrm{~V}$ und einem Strom von 400 mA durchgeführt. Die anschließende Färbung erfolgte im Ethidiumbromid-Bad (ca. 10min Färbung, 10min Entfärbung in Wasser). Das gefärbte Gel wurde dann über einer UV-Bank (M-20 UV Benchtop Transilluminator, UVP INc., Upland, California, USA) mit einer Olympus Camedia C5050-Digitalkamera fotografiert. 


\section{“Polymerase Chain Reaction" (PCR)}

Für die PCR wurde bei den meisten Proben die „Primer“-Kombination 1F-1351R eingesetzt (Abb. 2.1, Anhang Tab. 7.4). Bei einigen Proben, die mit dieser Kombination kein Produkt lieferten, weil $1 \mathrm{~F}$ nicht binden konnte, wurde die Kombination M34-1351R verwendet. Eingangs wurden für einige Proben drei separate PCRs mit den „Primer“-Kombinationen 1F-636R, 440F-888R und 645F1351R durchgeführt. Dies erwies sich später als unnötig, da das Gesamtfragment 1F-1351 bzw. M34-1351 amplifizierbar ist. Für die PCR wurden PuReTaq ReadyTo-Go PCR Beads (GE Healthcare) genutzt. Diese fertigen Ansätze enthalten alle für die PCR notwendigen Reagenzien, inklusive Polymerase. Lediglich Wasser, „Primer" und DNA müssen hinzu gegeben werden. Pro acht Reaktionen wurden $4 \mu \mathrm{l}$ jedes „Primer“ (Konzentration jeweils $10 \mu \mathrm{M}$ ) und $100 \mu \mathrm{l}$ Wasser (HPLC-Qualität) zu einer „Primer“-Lösung zusammengestellt und sorgfältig gemischt. Für jede Reaktion wurden erst 12,5 $\mu \mathrm{l}$ der o. g. „Primer“-Lösung, dann 12,5 $\mu$ lder extrahierten DNA in einem 200 $\mu$ l-Reaktionsgefäß auf ein Taqbead gegeben. Sofort nach dem Auflösen des Taqbead wurde die Lösung kurz zentrifugiert und im Thermocycler mit folgendem PCR-Programm behandelt:

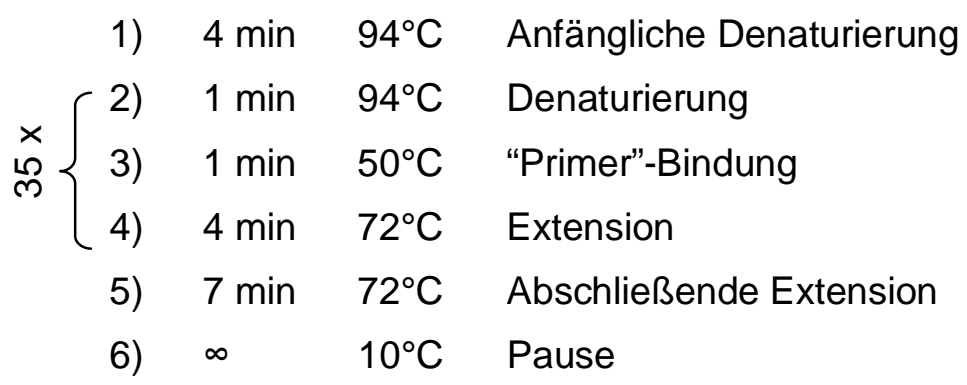

Dabei wurden Schritt 2-4 in 35 Zyklen wiederholt. Als Thermocycler diente entweder ein TGradient oder ein TPersonal der Firma Biometra.

Der Erfolg der PCR wurde mittels Gelelektrophorese (s.o.) überprüft.

Bei Vorhandensein einer starken, diskreten DNA-Bande im Gel wurde die PCRReaktion aufgereinigt. Dafür wurden Montage PCR Centrifugal Filter Devices (Millipore, Schwalbach/ Ts.) verwendet. Wegen der hohen Viskosität der Lösung wurden bei der Bindung der DNA an die Säule Zentrifugationszeit und Rotationsfrequenz erhöht (20-30 min bei $5600 \mathrm{U} / \mathrm{min}$ ), ansonsten die Gebrauchsanweisung befolgt.

Mittels Gelelektrophorese (s. o.) wurde überprüft, wie hoch die DNA-Menge im Vergleich zu einer Referenzprobe ist, die in einer früheren Sequenzreaktion ein gutes Ergebnis geliefert hat. 


\section{Sequenzierung}

Für die Sequenzierreaktion nach der Kettenabbruchmethode wurde das $\mathrm{ABI}$ PRISMTM Bigdye Terminator Cycle Sequencing Ready Reaction Kit (Applied Biosystems) verwendet. Aus 2,3 $\mu \mathrm{l} \mathrm{Big} \mathrm{Dye} \mathrm{-} \mathrm{Lösung} \mathrm{und} \mathrm{5,7} \mu$ l Sequenzierungspuffer pro Reaktion wurde eine Reaktionslösung zusammengestellt. Für jede Sequenzierreaktion wurden 1,5 $\mu \mathrm{l}$ des „Primer“, $8 \mu$ l Reaktionslösung und 1-3 $\mu$ l PCR-Produkt in einem $200 \mu$ l-Reaktionsgefäß zusammengestellt und mit Wasser (HPLC-Qualität) auf ein Gesamtvolumen von $20 \mu \mathrm{l}$ gebracht. Die Menge der eingesetzten DNA richtete sich nach der Bandenstärke des aufgereinigten PCR-Produkts in der Gelelektrophorese. Der fertige Ansatz wurde kurz zentrifugiert. Für die Sequenzreaktion fanden dieselben Thermocycler wie für die PCR Verwendung. Folgendes PCR-Programm wurde durchlaufen:

\begin{tabular}{|c|c|c|c|}
\hline 1) & $4 \min$ & $96^{\circ} \mathrm{C}$ & Anfängliche Denaturierung \\
\hline$(2)$ & $30 \mathrm{sec}$ & $96^{\circ} \mathrm{C}$ & Denaturierung \\
\hline 3) & $15 \mathrm{sec}$ & $50^{\circ} \mathrm{C}$ & "Primer"-Bindung \\
\hline 4$)$ & $4 \min$ & $60^{\circ} \mathrm{C}$ & Extension \\
\hline 5) & $\infty$ & $10^{\circ} \mathrm{C}$ & Pause \\
\hline
\end{tabular}

Als „Primer" dienten alle in Abb. 2.1 / Tab. 7.4 aufgeführten Oligonukleotide. Bei den Proben, deren PCR mit M34 durchgeführt wurde, wurde auch bei der Sequenzierung dieser „Primer“ benutzt. Auf diese Weise wurden je Probe sechs Sequenzen erzeugt.

Das Produkt der Sequenzreaktion wurde mit einer Ethanol-Fällung nach Sambrook \& Russell (2001:A8.12) konzentriert. Dafür wurde das komplette Produkt (20 $\mu$ l) mit $80 \mu \mathrm{l}$ Natriumacetat $(0,3 \mathrm{M}, \mathrm{pH} 5,2)$ und $300 \mu \mathrm{l}$ Ethanol (96\%) gemischt, 20 min bei Raumtemperatur inkubiert und anschließend zentrifugiert $\left(1 \mathrm{~h}, 4^{\circ} \mathrm{C}, 13^{\prime} 000 \mathrm{rpm}\right)$. Anschließend wurde der Überstand zügig entfernt, $100 \mu$ l Ethanol (76\%) auf das

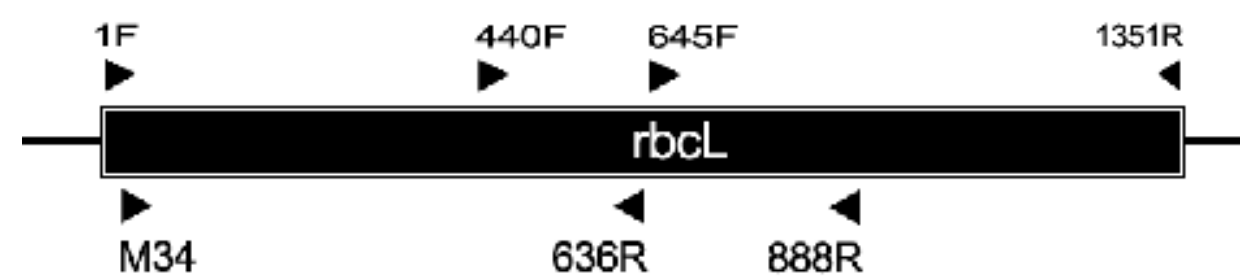

Abb. 2.1: Binde-Position und Amplifikations-Richtung der als „Primer“ verwendeten Oligonukleotide im rbcL-Gen. 
Pellet gegeben und erneut zentrifugiert $\left(1 \mathrm{~h}, 4^{\circ} \mathrm{C}, 13^{\prime} 000 \mathrm{rpm}\right)$. Der Überstand wurde entfernt und das Pellet bei $65^{\circ} \mathrm{C}$ kurz (ca. $5 \mathrm{~min}$ ) getrocknet (exaktes Protokoll nach Rohwer \& Rudolph, unpub.). Die gefällte DNA wurde bei Raumtemperatur gelagert und an ein externes Labor (Universitätsklinikum Eppendorf, Hamburg) weitergegeben. Dort wurde das Fragmentgemisch auf einem ABI 3100 Automated Capillary DNA Sequencer elektrophoretisch getrennt und chromatographisch ausgelesen.

Die resultierenden $\mathrm{ABI}$-Chromatogrammdateien wurden mit dem Programm Sequencher 3.1.1 (Gene Codes Corporation) bearbeitet. Die vom ABI automatisch erkannte Sequenz wurde z. T. manuell korrigiert. Mit demselben Programm wurden die Teilsequenzen einer Probe zu einer Gesamtsequenz zusammengefügt und im GenBank-Format ( $\left.{ }^{*} . \mathrm{gb}\right)$ abgespeichert.

\subsection{Erstellen der Datenmatrix (,Alignment“)}

Die Sequenzdateien wurden mit dem Programm BioEdit 7.0.5.3 (http://www.mbio.ncsu.edu/BioEdit/bioedit.html) ins „Alignment“ gebracht. Dies war ohne Alignment-Algorithmus durch Verschieben per Hand möglich. Zur der resultierenden Matrix wurden auf die gleiche Weise 66 Sequenzen aus der "GenBank“ (http://www.ncbi.nlm.nih.gov/) hinzugefügt (s. Anhang Tab. 7.4). Das Alignment wurde so zugeschnitten, dass nur komplette Codons enthalten sind.

\subsection{Phylogenie-Rekonstruktion}

Als Außengruppe für die Analysen wurde jeweils Bommeria ehrenbergiana gewählt, da $B$. ehrenbergiana zur Schwestergruppe des Clade gehört, in den die hier untersuchten Arten fallen (vgl. Gastony \& Rollo 1995).

Mit dem Programm PAUP* 4.0b10 (Swofford 2003) wurde eine PhylogenieRekonstruktion unter Anwendung des Sparsamkeitskriteriums „Maximum Parsimony" vorgenommen. Dafür wurde eine heuristische Suche mit 10000 Replikaten durchgeführt. Pro Replikat wurde eine Ausgangstopologie durch „Random Sequence Addition“ erzeugt. Diese Topologie wurde mit dem „branch swapping“Algorithmus TBR (,tree bisection reconnection“) umgeordnet und die so erzeugten Topologien auf die vorliegende Anzahl von Substitutionsschritten untersucht. Die Optionen MULPARS und „steepest decent“ wurden genutzt, um mit hoher Wahrscheinlichkeit alle sparsamsten Bäume zu finden.

Die resultierenden Bäume wurden mit dem PAUP*-Befehl pscores analysiert. Die kürzesten Bäume wurden zu einem „Strict Consensus“ verrechnet. 
Des Weiteren wurde eine „Bayesian Inference of Phylogeny“ mit MrBayes 3.1.2 (Huelsenbeck \& Ronquist 2001; Ronquist \& Huelsenbeck 2003) durchgeführt. Für diese Analyse wurde ein Codon-Modell (Muse \& Gaut 1994, Goldman \& Yang 1994) angesetzt. Die „Markov Chain Monte Carlo“-Analyse (MCMC) lief in vier parallelen Ketten mit jeweils $10^{6}$ Generationen und einer Beprobungsrate von jeder hundertsten. Die Berechnung des zugehörigen „Consensus“ mit „Posterior Probability“Werten erfolgte direkt in MrBayes. Nach graphischer Überprüfung der InL-Werte wurden die ersten 2500 Topologien als „Burnin“ verworfen.

\subsection{Statistische Tests}

In PAUP* wurde eine „Bootstrap“-Analyse (Felsenstein 1985) unter Anwendung von „Maximum Parsimony“ mit 1000 Pseudoreplikaten durchgeführt. Dafür wurde die gleiche Suchstrategie wie bei der Phylogenie-Rekonstruktion verfolgt, das „branch swapping“ allerdings auf $10^{6}$ Umordnungen pro „Stepwise Addition“-Replikat begrenzt.

Außerdem wurde eine „Bootstrap“-Analyse mit dem Wahrscheinlichkeits-Kriterium „Maximum Likelihood“ durchgeführt. Dafür wurde GARLI 0.951 (Zwickl 2006) verwendet. Mit Modeltest (Posada \& Crandall 1998) wurde für den Datensatz das Evolutionsmodell „General Time Reversible“ mit einem Anteil invariabler Positionen und Gamma-Verteilung $(\mathrm{GTR}+\mathrm{I}+\Gamma)$ als geeignetes Modell gefunden. Dieses wurde in GARLI angenommen und alle Parameter während des Laufs durch das Programm ermittelt. 100 Pseudoreplikate wurden ausgeführt, die resultierenden Topologien anschließend in PAUP* geladen und zu einem „Majority Rule-Consensus“ verrechnet. Die resultierenden „Majority Rule“-Werte sind die „Bootstrap“-Unterstützungen.

Alle Topologien wurden als NEXUS-Dateien abgespeichert und mit dem Programm MrEnt 1.2.1 (Zuccon \& Zuccon 2006) graphisch nachbearbeitet. 


\section{Ergebnisse}

\subsection{Datenmatrix}

Die Homologisierung der Sequenzen (Alignment) ergab eine Matrix mit 79 Zeilen (=Sequenzen) und 1323 Spalten (=orthologe Nukleotidpositionen). Keine Sequenz weist Insertionen oder Deletionen auf. Die vollständige Länge des Alignments wird nicht von allen Sequenzen erreicht. Der mittlere Bereich, in dem alle Sequenzen vorhanden sind, erstreckt sich über 1140 Positionen. Von den 1323 Spalten sind 935 konstant, weisen also in allen vorhandenen Zeilen das gleiche Nukleotid auf. Unter den übrigen, variablen Spalten sind 256 „Parsimony“-informativ. Die restlichen 132 sind „Parsimony“-uninformativ, ergeben also in allen möglichen Topologien nur Autapomorphien.

\subsection{Phylogenetische Untersuchung}

\subsubsection{Topologien}

Die Analyse der Matrix unter Verwendung des Sparsamkeitskriteriums („Maximum Parsimony“, MP) erbrachte 96 sparsamste Topologien mit einer Länge von jeweils 1134 Schritten. Diese Topologien haben einen "Consistency Index" von $\mathrm{Cl}=0,426$, einen „Retention Index“ von $\mathrm{Rl}=0,691$, einen „Rescaled Consistency Index“ von $\mathrm{RC}=0.295$ und einen „Homoplasy Index“ von $\mathrm{HI}=0,574$. Abb. 7.2 (Anhang) zeigt eine aus den sparsamsten Topologien berechneten „Strict Consensus“.

Die „Bayesian Inference of Phylogeny“ ergab nach $10^{6}$ Generationen eine „average standard deviation of split frequencies" von $\sigma=0.051287$. Der empfohlene Wert nach Ronquist et al. (2005:9) ist <0.01. Die Logarithmen der Wahrscheinlichkeitswerte streuen in den späten Generationen der MCMC-Kette allerdings sichtbar um eine Konstante, was darauf schließen lässt, dass die Ketten stationär geworden sind (Ronquist et al. 2005:21). Der Majority-Rule-Consensus aller gespeicherten Topologien, abzüglich 25\% Burnin, ist in Abb. 3.1 dargestellt. Die Innengruppe gliedert sich hier ebenfalls in 66 Knoten.

Die MP- und die „Bayesian“-Topologie haben 53 Knoten gemeinsam. Jede der beiden Topologien widerspricht der anderen an zehn Knoten. 


\subsubsection{Statistische Tests}

Der „Bootstrap“ unter Verwendung von „Maximum Parsimony“ (MPBS) ergab für 40 Knoten (Innengruppe) einen Unterstützungswert $\geq 70$. Das entspricht $61 \%$ der Knoten, die in der Phylogenierekonstruktion unter MP erhalten worden sind. Alle Unterstützungswerte MPBS $\geq 60$ sind in Abb. 7.2 an den jeweiligen Knoten angegeben.

Das Resultat der „Bootstrap“-Analyse unter ML ergab für 36 Knoten (Innengruppe) eine Unterstützung von MLBS $\geq 70$ (s. Anhang Abb. 7.3). Diese Knoten widersprechen in keinem Fall der unter MP erhaltenen Topologie.

Die bei der „Bayesian Inference“ erhaltene „Bayesian Posterior Probability“ (BPP) wird ebenfalls als Unterstützungswert interpretiert. Hier wurde in der Innengruppe von 42 Knoten der „Bayesian“-Topologie eine BPP $\geq 0,95$ erreicht. Das entspricht $64 \%$ der gesamten Innengruppe. Abb. 7.4 (Anhang) zeigt die „Bayesian“-Topologie mit BPP-Unterstützungswerten.

Zusammenfassend: 32 Knoten der Innengruppe haben MPBS $\geq 70$, MLBS $\geq 70$ und BPP $\geq 95$ (im Weiteren „dreifach unterstützt“). Sechs Knoten sind durch zwei Methoden unterstützt (,zweifach unterstützt“): Zwei mit MLBS+BPP, zwei mit MLBS+MPBS und zwei mit MPBS+BPP. Zehn Knoten sind nur bei einer Methode unterstützt („einfach unterstützt"): Sechs nur bei BPP, vier nur bei MPBS und keiner nur bei MLBS. Aus dieser Verteilung ergibt sich die Linienstärke in Abb. 3.1.

\subsubsection{Position der neu untersuchten Spezies}

In der durch „Bayesian Inference of Phylogeny“ erhaltenen Topologie (Abb. 3.1, 3.2) lässt sich folgende Grundstruktur erkennen, die als Orientierung dienen kann, um die Position der Taxa aus dem südlichen Afrika zu beschreiben:

Die Innengruppe untergliedert sich in einen dreifach unterstützten Clade (Spezies 1 59) und dessen nicht unterstützte Schwestergruppe (60-77).

Spezies 1-59 sind wiederum in zwei dreifach unterstützte Clades gegliedert. Der eine davon besteht aus nur drei Spezies (57-59). Der andere (1-56) zeigt eine Polytomie aus einem dreifach unterstützten Clade (35-55), einem zweifach unterstützten Clade (1-20), einem nicht unterstützten Clade (21-34) und Aspidotis californica (56). Spezies 21-34 gliedern sich in einen dreifach unterstützten Clade (30-34) sowie dessen nicht unterstützte Schwestergruppe aus südafrikanischen Spezies (21-29). MP liefert hier ein abweichendes Ergebnis, in dem der südafrikanische Clade näher mit 1-20 und $A$. californica gruppiert, und erst nachrangig mit 30-34 (Abb. 7.2). 
Die oben erwähnte Gruppe aus Spezies 60-77 besteht aus einem dreifach unterstützten Clade (60-71) und dessen zweifach unterstützter Schwestergruppe (72-77). Die beschriebenen Clades beinhalten zahlreiche weitere, teils dreifach unterstützte und aussagekräftige Gruppierungen.

Die südafrikanischen Taxa gruppieren an folgenden Stellen:

- Cheilanthes capensis (Thunb.) Sw., Cheilanthes deltoidea Kunze, Cheilanthes hastata (L.f.) Kunze, Cheilanthes cf. kunzei Mett., Cheilanthes robusta (Kunze) Tryon, Cheilanthes contracta (Kunze) Mett. ex Kuhn, Cheilanthes parviloba (Swartz) Swartz, Cheilanthes marlothii (Hieron.) Schelpe und Cheilanthes dinteri Brause bilden den o. g. rein südafrikanischen Clade (Spezies 21-29). Der Clade beinhaltet drei dreifach unterstützte Paare: Ch. capensis mit Ch. deltoidea $(84,6 / 88 / 1,00=$ MPBS/MLBS/BPP $)$, Ch. contracta mit Ch. parviloba $(100 / 100 / 1,00)$ sowie Ch. hastata mit Ch. cf. kunzei $(72,8 / 88 / 1,00)$. Ferner ist die Gruppierung aus C. dinteri, C. marlothii, C. parviloba und C. contracta mit $\mathrm{BPP}=1,00$ gestützt.

- Cheilanthes multifida subsp. multifida (Swartz) Swartz, Pellaea pteroides (L.) Prantl und Pellaea calomelanos (Swartz) Link (Spezies 52, 53, 55) stehen relativ basal in einem Clade mit Doryopteris sect. Doryopteris/Lytoneuron, Pellaea sect. Ormopteris, Trachypteris pinnata und zwei südamerikanischen CheilanthesArten $(50,54)$. Doryopteris sect. Doryopteris (34-42) bildet dabei eine dreifach unterstützte Einheit, und ein gemeinsamer Clade aus Doryopteris sect. Lytoneuron (43-45) und Pellaea sect. Ormopteris (46-49) ist zweifach unterstützt. Als schlecht aufgelöster Rest des Clade bleiben Tr. pinnata, die brasilianischen Cheilanthes-Arten und die drei südafrikanischen Spezies. Innerhalb dieser Gruppe ist nur die Paarung von P. pteroides und Ch. multifida unterstützt, und zwar dreifach $(90,0 / 80 / 0,96)$.

- Pellaea rufa A.Tryon (Spezies 65) steht inmitten eines dreifach unterstützten Clade aus Pellaea sect. Pellaea/Platyloma, Paragymnopteris, Astrolepis und Argyrochosma sensu Kirkpatrick (2007). Dort steht sie in einer dreifach unterstützten Zweiergruppe $(93,3 / 90 / 1,00)$ mit Pellaea andromedifolia (Kaulf.) Fée.

- Cheilanthes rawsonii (Pappe) Mett. ex Kuhn (Spezies 75) gruppiert in einem Clade amerikanischer Cheilanthes-Arten (72-77). Seine Gruppierung mit Ch. lanosa (Michx.) D.C.Eaton ist dabei dreifach unterstützt $(95,0 / 96 / 1,00)$. 
Die hier erstmals untersuchte Spezies Cheilanthes pulchella Bory ex Willd. von den Kanarischen Inseln gruppiert in den Clade aus Spezies 1-20. Alle anderen Spezies dieses Clade sind asiatischer Herkunft. Die genaue Position von Ch. pulchella ist unklar, da sie zwar in „Bayesian Inference“ eine einfach unterstützte Gruppe mit Cheilanthes chinensis (Baker) Domin und Cheilosoria patula (Baker) P.S.Wang bildet, im MP-Ergebnis aber alleine als Schwester zum Rest des Clades steht (in dem dann die Paarung aus Cheilanthes chinensis und Cheilosoria patula die basalste Position hat).

Abb. 3.1 (Seite 23): Consensus-Topologie einer „Bayesian Inference of Phylogeny“ auf Basis von 78 rbcL-Sequenzen cheilanthoider Farne. Mit einem Asterisk (*) gekennzeichnete Gruppierungen widersprechen der Consensus-Topologie einer MP-Analyse desselben Datensatzes (Abb. 7.6). Die Linienstärke der Äste zeigt deren Unterstützung durch „Maximum Parsimony Bootstrap“, „Maximum Likelihood Bootstrap“ und „Bayesian Posterior Probability“:__ = Unterstützung durch ein Verfahren, $=$ Unterstützung durch zwei Verfahren, = Unterstützung durch drei Verfahren.

Abb. 3.2 (Seite 24): Consensus-Topologie einer „Bayesian Inference of Phylogeny“ von $78 \mathrm{rbcL}$ Sequenzen cheilanthoider Farne. Die farbige Markierung zeigt die Herkunft der sequenzierten Proben (ausgenommen Spezies 31-33: Daten aus der Missouri Botanical Garden - w3 - Specimen Data Base und Spezies 36: pantropische Verbreitung). 


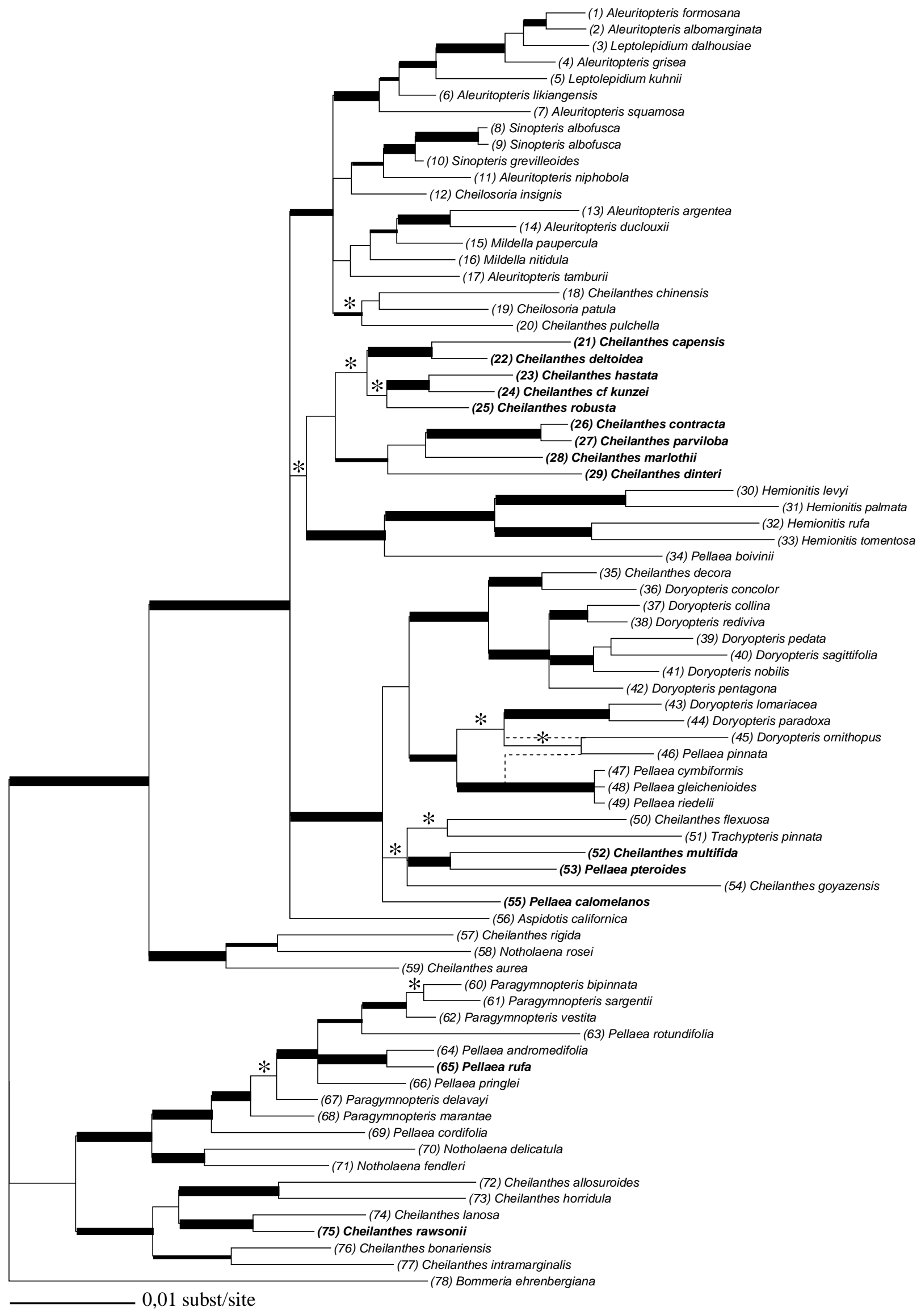




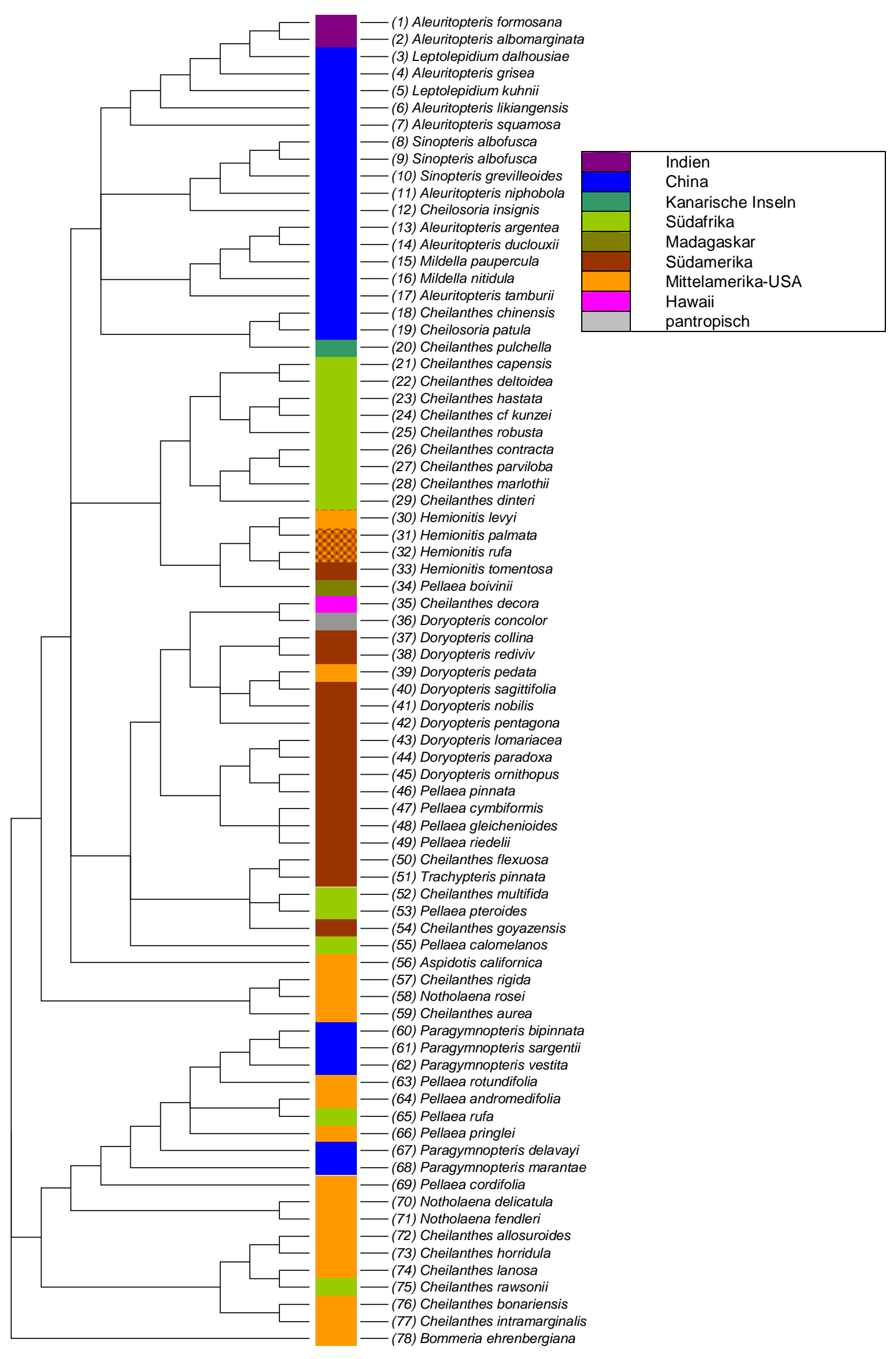




\section{Diskussion}

\subsection{Phylogenie}

Da die erhaltene Phylogenie (Abb. 3.1) lediglich auf rbcL-Daten beruht, kann das Ergebnis insgesamt nur als vorläufig gewertet werden (siehe dazu Schuettpelz et al. 2007:1180). Taxonomische Konsequenzen können erst auf der Basis von durchgehend widerspruchsarmen und gut auflösenden Topologien gezogen werden. Um dies zu erreichen, könnten ergänzend zu $r b c L$ weitere DNA-Regionen ausgewertet werden, z. B. rps4, rps4-trnS IGS und trnL-F IGS.

Allerdings stimmt die vorliegende Topologie mit den jeweils entsprechenden Ergebnissen anderer Autoren weitgehend überein. Da die Datenquellen hinsichtlich der untersuchten Arten und der gewählten DNA-Regionen differieren, erhöht die Übereinstimmung die Plausibilität.

Die Auswertung von drei prinzipiell unterschiedlichen Verfahren der PhylogenieRekonstruktion (Tab. 1.1, Anhang Abb. 7.2-4) ermöglicht die Beurteilung der ModellUnabhängigkeit der Ergebnisse.

Zur Bewertung von Gruppierungen wird betrachtet, ob die Unterstützungswerte oberhalb von Akzeptanzschwellen (BS $\geq 70, B P P \geq 95)$ in Anlehnung an Schuettpelz et al. (2007) liegen (Abb. 3.1). Die höhere Akzeptanzschwelle für „Posterior Probabilities“ trägt der Beobachtung Rechnung, dass diese systematisch höher sind als „Bootstrap“-Werte (Erixon et al. 2003). Diejenigen Gruppierungen, die nach der vorliegenden Bewertung "dreifach“ unterstützt sind (Abb. 3.1), sind auch in Bezug auf die statistischen Tests nicht vom angewendeten Kriterium bzw. Modell abhängig. Sie sind mit Sicherheit robust im rbcL-Datensatz enthalten. Auch eine Unterstützung durch ein einziges Testverfahren kann als ausreichend angesehen werden, dies setzt aber voraus, dass das zugrunde liegende Modell der Sequenzevolution den Datensatz optimal erklärt. Modell-unabhängig („dreifach“) unterstützte Gruppierungen sind vor dem Hintergrund, dass hier keinem Modell bzw. Kriterium begründet Vorzug gegeben werden kann, plausibler als „zweifach“ oder „einfach“ unterstützte. Generell handelt es sich dabei um Datensatz-immanente Unterstützungswerte, durch die systematische Fehler (wie z. B. mangelnde Repräsentativität der untersuchten DNA-Region) nicht sichtbar werden. Deshalb müssen bei einer abschließenden Bewertung von Gruppierungen externe Kriterien (morphologische Merkmale) so weit wie möglich mit berücksichtigt werden. 
Cheilanthes capensis-Gruppe (Spezies 21-29 in Abb. 3.1): Die südafrikanischen Spezies 21-29 werden von allen Analysemethoden in einem eigenen Clade zusammengefasst, der aber nur mit der „Bayesian Posterior Probability“ eine nennenswerte Unterstützung erreicht (vgl. Abb. 7.8). Diese liegt mit $\mathrm{BPP}=0,93$ nur knapp unter der angesetzten Akzeptanzschwelle von 0,95. Dass der Clade von beiden Methoden der Phylogenierekonstruktion gefunden wurde (Abb. 3.1, 7.6) deutet darauf hin, dass die entsprechende Information im Datensatz enthalten - und nicht Artefakt einer Methode - ist. Die fehlende Unterstützung durch den „Bootstrap“ zeigt, dass das zugrunde liegende phylogenetische Signal schwach ist. Dies könnte von einer schnellen Folge von Speziationen herrühren, zwischen denen sich nur wenige Merkmalsveränderungen ansammeln konnten. Diese Erklärung ist mit den kurzen Astlängen im basalen Teil des Clade kompatibel (Abb. 3.1). Ein wesentlicher Schritt für die Absicherung des Clade wäre das Auffinden von nichtmolekularen Synapomorphien. Das ist aber derzeit schwierig, da die Position des Clade innerhalb der Großgruppe aus Spezies (1-56) unklar bleibt. Um den Clade (21-29) morphologisch zu umschreiben, ist also eine gute Kenntnis von Spezies 1-56 notwendig, da keine Schwestergruppe bekannt und somit keine kleinere Außengruppe als Spezies 1-20 und 30-56 verfügbar ist. Auf eine so umfängliche Betrachtung soll hier verzichtet werden, zumal die Hoffnung besteht, in Zukunft eine eindeutige molekulare Phylogeniehypothese für die Clades innerhalb von Spezies 1-56 zu finden. Diese Großgruppe ist nicht nur im vorliegenden Ergebnis sehr gut unterstützt, sondern wurde auch durchgehend bei früheren molekularen Untersuchungen gefunden (auch auf Basis anderer DNA-Abschnitte, vgl. Kirkpatrick 2007, Schuettpelz et al. 2007). Die innerhalb der Großgruppe gefundenen Clades stimmen zwar in den Ergebnissen unterschiedlicher Untersuchungen weitgehend überein, ihre Position zueinander stellt sich aber sehr verschieden dar (vgl. Kapitel 1.2). Selbst innerhalb der vorliegenden Untersuchung unterscheiden sich die Ergebnisse der MP- und „Bayesian“-Analyse. Diese Diskrepanz ist überraschend, da „Bayesian Inference“ und „Maximum Parsimony“ meist gleiche Topologien liefern. Der Datensatz enthält bezüglich der Position des Clade (21-29) offenbar keine eindeutige Information, sodass die Wahl des Optimalitätskriteriums und/oder der betrachteten Informationseinheit (Nukleotid oder Codon) einen Einfluss auf die resultierende Topologie hat. Es ist unklar, welches der beiden Verfahren die molekulare Evolution des rbcL-Gens besser nachzeichnet. Man könnte dem Codon-Modell den Vorzug geben, da es die Funktion des rbcL-Gens berücksichtigt. Andererseits resultieren unter Verwendung dieses Modells Speziesgruppen als paraphyletisch, die demselben traditionellen Taxon angehören und bei MP monophyletische Gruppen bilden (Spezies 43-45, 46- 
49, 67-68). MP hat also insgesamt die höhere Kongruenz mit der traditionellen Taxonomie. Keines der beiden angewendeten Verfahren kann hier eindeutig vorgezogen werden. Das Schwestergruppenverhältnis des Clade (21-29) zu Hemionitis und Pellaea boivinii (30-34, Abb. 3.1) ist somit nur ein mögliches, kein verlässliches Ergebnis. Der untersuchte Datensatz reicht nicht aus, die Beziehungen zwischen den Clades innerhalb der Großgruppe (1-56) aufzulösen.

Aus der Artengruppe 21-29 ist lediglich Cheilanthes parviloba früher molekular untersucht worden (Kirkpatrick 2007). Das von Kirkpatrick erhaltene Ergebnis bestätigt die Zugehörigkeit zu der Großgruppe 1-56, erlaubt aber keine Aussage über die exakte Position. In ihrem Datensatz fehlen unter anderem Hemionitis und die asiatischen Cheilanthes-Arten. Moran \& Smith (2001:315) beschrieben eine große morphologische Ähnlichkeit zwischen Ch. deltoidea, Ch. capensis (im vorliegenden Ergebnis Schwesterspezies) und zwei neuweltlichen Cheilanthes-Arten: Ch. brandegeei D.C.Eaton und Ch. fractifera R.M.Tryon. Die beiden letztgenannten Arten sind bislang nicht molekular untersucht worden, sodass sich hieraus ebenfalls kein Hinweis ergibt. Die Einbeziehung dieser Spezies in eine molekulare Phylogenie könnte zur Klärung der Position von Clade (21-29) aber sehr hilfreich sein.

Wenngleich eine Beurteilung des gesamten Clade (21-29) aufgrund morphologischer Merkmale noch schwierig ist, ist sie für die Gruppen innerhalb des Clade möglich. Die detaillierten Beschreibungen der südafrikanischen Arten durch Anthony (1984) bieten hierfür eine gute Grundlage.

Die Verwandtschaft von Ch. capensis und Ch. deltoidea wird morphologisch durch folgende Merkmale gestützt: Rhizomschuppen (einfarbig), Blattschnitt (basale Fiedern am größten und nach unten verbreitert) und Struktur des Sporoderms (Anthony 1984). Die ersteren zwei Punkte wurden auch von Moran \& Smith (2001:315) genannt, darüber hinaus noch ein „dünnes, weißliches und breites Indusium“, ein Blattwurfgewebe, über das keine Daten für andere Spezies vorliegen, sowie ein ventral gefurchter Wedelstiel. Das hier untersuchte Exemplar von Ch. deltoidea, sowie weitere Aufsammlungen aus derselben Region, zeigen allerdings einen drehrunden Stiel. Die systematische Bedeutung der Wedelstielfurchung ist fraglich (Anthony 1984:57), möglicherweise ist das Merkmal auch taxonomisch wertlos.

Die Verwandtschaft von Ch. hastata (Abb. $4.1 \mathrm{C}$ ) und Ch. kunzei ist durch gemeinsame Merkmalsausprägungen des Wedelstiels (kürzer als die Spreite und in der oberen Hälfte gefurcht), der Rhachis (gefurcht und im oberen Teil der Spreite geflügelt) und des Blattschnitts (unterste Fiedern reduziert) gestützt (vgl. Anthony 1984). 
Ch. parviloba und Ch. contracta weisen Gemeinsamkeiten in folgenden Merkmalen auf: Rhizomschuppen (kastanienfarben gestreift), Wedelstiel (kürzer als die Spreite, drehrund und multizellulär behaart), Blattschnitt (unterste Fiedern reduziert), Sori (diskret), Blattrand (umgerollt) und Struktur des Sporoderms (Anthony 1984).

Die molekular nicht unterstützte Gruppierung (Ch. marlothii (Ch. parviloba, Ch. contracta)) ist aus morphologischer Sicht plausibel. Während diese drei Spezies den drehrunden behaarten Blattstiel, die reduzierten basalen Fiedern und die gestreiften Rhizomschuppen teilen, hat Ch. dinteri einen gefurchten beschuppten Blattstiel, maximal große basale Fiedern und einfarbige Rhizomschuppen (vgl. Anthony 1984). Die Arten der einfach unterstützten Vierergruppe besitzen allerdings als gemeinsames Merkmal diskrete Sori.

$\mathrm{Ob}$ Ch. robusta eher an der Basis der zuletzt beschriebenen Vierergruppe steht (MP-Ergebnis) oder basal zu Ch. hastata und Ch. kunzei (,Bayesian Inference“), kann auf Basis der verfügbaren morphologischen Merkmale nicht entschieden werden. Die geflügelte Mittelrippe ist ein Indiz für letztere Variante, eine Nähe zu Ch. dinteri ist aber auch zu rechtfertigen.

Es fällt auf, dass Merkmale des Indusiums, der Sori und des Induments, drei augenfällige Merkmalsbereiche, hier wenige mögliche Synapomorphien bieten. Anthony (1984:1) stellte den systematischen Wert der Kontinuität des Indusiums in Frage, was sich hier vollständig bestätigt: Ch. capensis hat z. B. ein zerteiltes Indusium, das von Ch. deltoidea ist kontinuierlich.

Cheilanthes multifida var. multifida, Pellaea calomelanos, $P$. pteroides (Spezies 52, 53, 55 in Abb. 3.1): Dass südafrikanische Spezies in den Trachypteris/Doryopteris/Ormopteris-Zusammenhang fallen, zeigten erstmals Gastony \& Rollo (1998). Dort resultierte Pellaea calomelanos als Schwesterspezies zu einem Clade aus Doryopteris und Trachypteris. Bei Zhang et al. (2007) gliedert sich diese Gruppe abweichend folgendermaßen: (Trachypteris ( $P$. calomelanos, Doryopteris)). Bei Schuettpelz et al. (2007) ergibt sich das entsprechende Bild mit Cheilanthes viridis: (Trachypteris (Adiantopsis (Ch. viridis, Doryopteris)). Im Ergebnis von Kirkpatrick (2007) tritt ein Clade aus P. calomelanos, Ch. viridis und

Abb. 4.1 (Seite 29): A, B: Cheilanthes multifida subsp. multifida in Paarl, Provinz Western Cape, Republik Südafrika. C: Cheilanthes hastata in Paarl (s. o.).

Fotos: T. Seaman, 07.10.2005.

Abb. 4.2 (Seite 30): A: Standort von Cheilanthes robusta bei Eksteenfontein, Richtersveld, Provinz Northern Cape, Republik Südafrika. B: Cheilanthes robusta am o. g. Standort.

Fotos: W. Eiserhardt, 11.10.2007. 


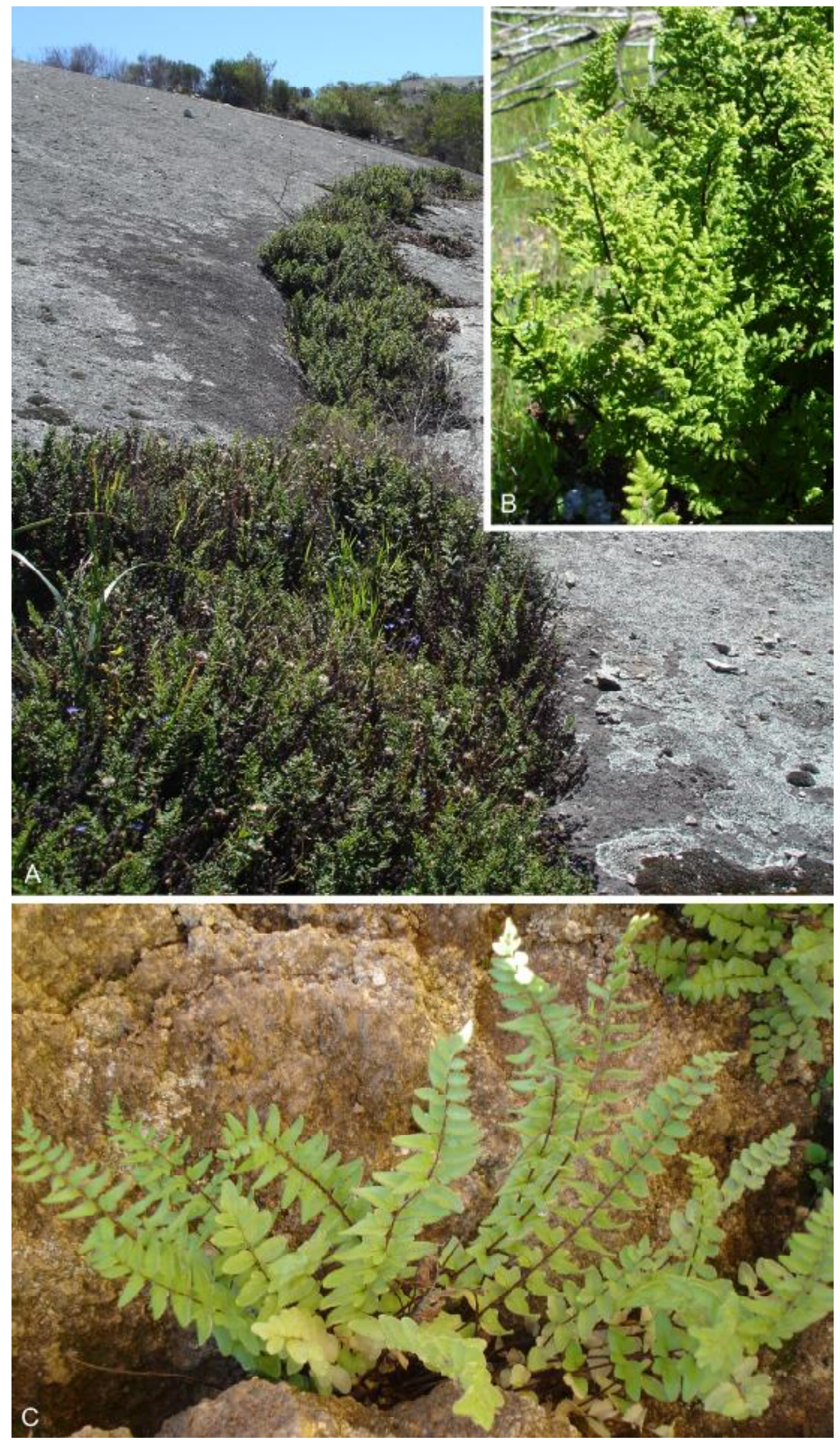




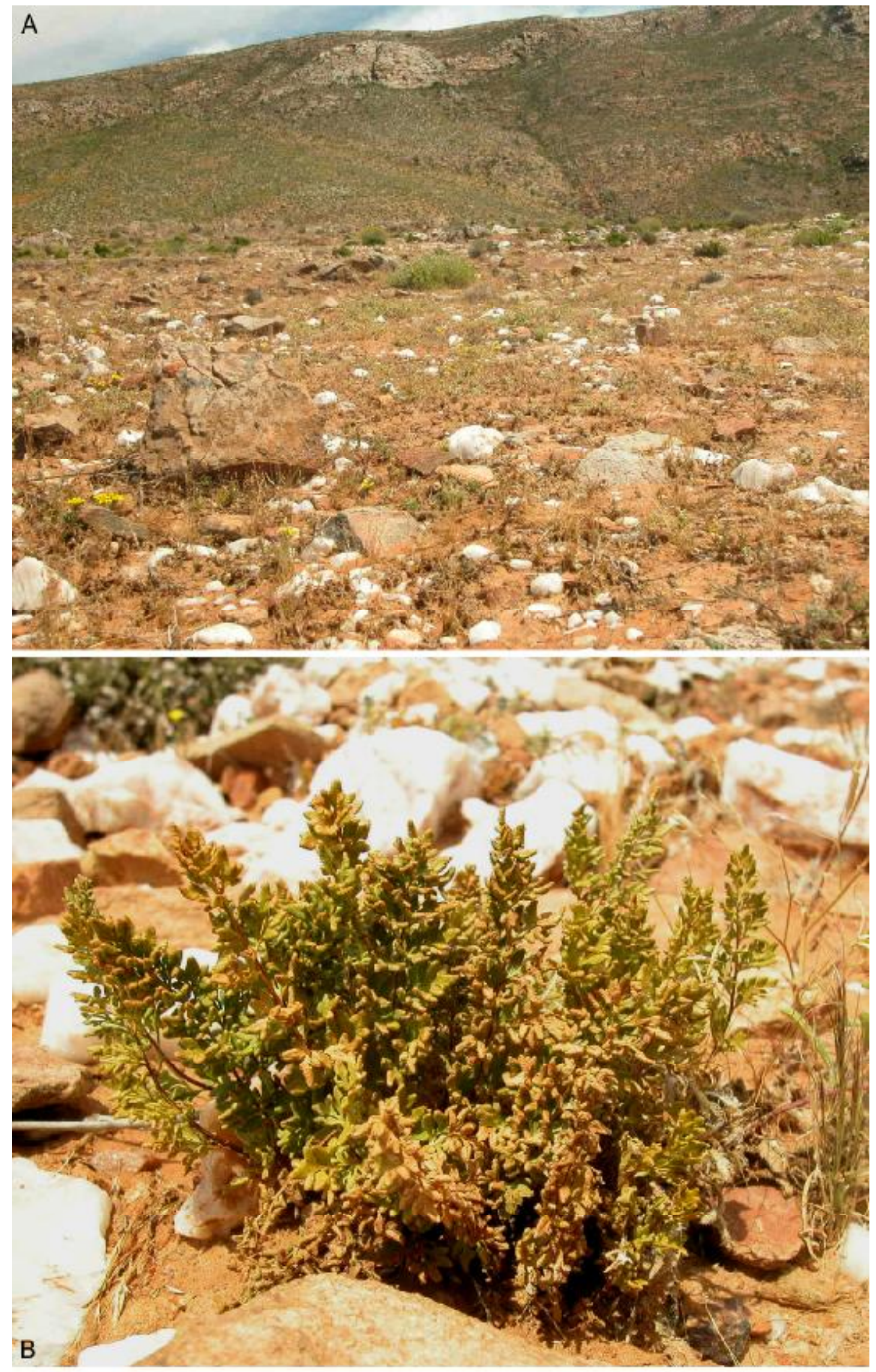


Ch. multifida subsp. lacerata auf. Trachypteris wurde von Kirkpatrick nicht untersucht. Wenn man - die von Kirkpatrick gefundene enge Verwandtschaft von $\mathrm{Ch}$. viridis und P. calomelanos im Sinn - die Ergebnisse von Gastony \& Rollo (1998), Zhang et al. (2007) und Schuettpelz et al. (2007) zusammenfasst, ist die Variante (Trachypteris (Adiantopsis („südafrikanische Spezies“, Doryopteris/ Ormopteris))) am plausibelsten.

Die Ergebnisse der vorliegenden Untersuchung tragen nicht zur Lösung dieses Problems bei, da der basale Bereich des Clade (35-55) nur wenig bzw. nicht signifikant unterstützte Auflösung zeigt. Neu ist, dass Pellaea pteroides ebenfalls in diesen Teil der Phylogenie fällt. Durch ihre gut gestützte Gruppierung mit $C h$. multifida subsp. multifida kann man eine Zugehörigkeit zu dem von Kirkpatrick (2007) gefundenen südafrikanischen Clade vermuten, der Ch. multifida subsp. lacerata enthält. Neu ist auch die Kombination der südafrikanischen Arten in einem Datensatz mit Ch. goyazensis und Ch. flexuosa (Prado et al. 2007). Diese beiden Cheilanthes-Arten fallen hier ins direkte Umfeld von $P$. pteroides, Ch. multifida und $P$. calomelanos, ohne eindeutige Gruppen mit diesen zu bilden.

Die enge Gruppierung von Ch. multifida (Abb. 4.1 A, B) und P. pteroides ist ein unerwartetes Ergebnis dieser Untersuchung (Koos Roux, pers. Mitt.). Pellaea pteroides nimmt unter den Cheilanthoideae morphologisch eine Sonderstellung ein, die dazu geführt hat, dass diese Spezies von unterschiedlichen Autoren Pellaea, Cheilanthes und einem eigenen Genus Choristosoria Mett. ex Kuhn zugeordnet wurde. Der zugrunde liegende Merkmalskonflikt bezieht sich nach Anthony (1984:226) auf die Pellaea-typische Spreite mit unpaarigen Fiedern, die den für Cheilanthes typischen diskreten Sori entgegensteht. Die Sporenmorphologie legt weder eine Zugehörigkeit zu Cheilanthes noch zu Pellaea nahe (ebd.).

Gemeinsam mit $C h$. multifida hat $P$. pteroides einen (dunkel-) kastanienfarbenen gefurchten Wedelstiel und ebensolche Rhachis. Die Lamina ist bei beiden Spezies fleischig-ledrig, ohne Indument und ohne sichtbare Nervatur. Eine weitere Gemeinsamkeit sind die deutlich abgesetzten Sori mit einzelnen, halbrunden, membrandünnen Indusia. Da sich Indusia, Sori und Indument bei den anderen südafrikanischen Spezies (s. o.) als phylogenetisch wenig bedeutende Merkmale herausgestellt haben, sind diese Gemeinsamkeiten als Synapomorphien aber fraglich.

Pellaea rufa (Spezies 65 in Abb. 3.1): Die Position der südafrikanischen Pellaea rufa inmitten von Arten von Pellaea sect. Pellaea wurde erstmals von Gastony \& Rollo (1998) mit rbcL-Sequenzen gezeigt. Das Ergebnis wurde anhand einer eigenen Sequenz bestätigt, da die Originalsequenz nicht verfügbar ist. Die 
Zugehörigkeit zu Pellaea sect. Pellaea entspricht der traditionelle Systematik (Tryon \& Tryon 1982:287). Auch die Verwandtschaft mit $P$. andromedifolia ist plausibel, da nach Tryon \& Tryon (1982:290) diese beiden Spezies, zusammen mit $P$. myrtillifolia Kuhn aus Chile, eine eng verwandte Gruppe bilden. Die Unterstützungswerte für die Gruppierung von $P$. rufa mit $P$. andromedifolia sind hier höher als bei Gastony \& Rollo und verleihen dem Ergebnis zusätzliches Gewicht.

Cheilanthes rawsonii (Spezies 75 in Abb. 3.1): Dass Cheilanthes rawsonii mit den restlichen südafrikanischen Cheilanthoideae nur entfernt verwandt ist, ist nicht unerwartet (Koos Roux pers. Mitt., Anthony 1984). Anthony (1984:10) stellte fest, dass die Sporenmorphologie keinerlei Verwandtschaft zu den anderen südafrikanischen Cheilanthoideae andeutet. Moran \& Smith (2001:316) haben beschrieben, dass Ch. rawsonii sich morphologisch kaum von der andinen $C h$. fraseri Kuhn unterscheidet.

Der Vergleich morphologischer Merkmale zwischen Ch. lanosa und Ch. rawsonii (Windham \& Rabe 1993:169 für Ch. lanosa, Anthony 1984:10 für Ch. rawsonii) ergibt keine so auffällige Übereinstimmung. Gemeinsame Merkmalsausprägungen sind ein ungefurchter Blattstiel und ebensolche Mittelrippe, Behaarung an Stiel, Mittelrippe und Spreite, Fehlen von Schuppen oberhalb der Blattstielbasis. Die Rhizomschuppen können bei beiden Spezies einfarbig oder gestreift sein. Die Sori sind in beiden Spezies diskret. Der Blattschnitt ist entfernt ähnlich, da beide Spezies hauptsächlich einfach gefiederte Wedel mit fiederschnittigen Fiedern zeigen. Bei Ch. lanosa ist der Wedel insgesamt ausladender und kann an der Basis zweifach gefiedert sein. Es sind auch deutliche Unterschiede erkennbar: Die auffallend dichte abaxiale Behaarung von $\mathrm{Ch}$. rawsonii fehlt bei Ch. lanosa. Bei letzterer Spezies ist die Lamina ab- wie adaxial nur spärlich behaart. Während Ch. lanosa über ein, wenngleich wenig ausgeprägtes, falsches Indusium verfügt, ist $C h$. rawsonii komplett exindusiat. Die Sori sind dort nahezu komplett vom abaxialen Tomentum bedeckt, welches offenbar die Schutzfunktion des Indusiums übernommen hat.

Der Schluss liegt nahe, Ch. lanosa und Ch. rawsonii zwar eng verwandt sind, der nächste Verwandte von $C h$. rawsonii aber noch nicht gefunden ist. Dies könnte mit hoher Wahrscheinlichkeit Ch. fraseri sein. 


\subsection{Phylogeographie}

Disjunktionen. Alle südafrikanischen Arten(-gruppen) haben nach Abb. 3.2 ihre nächsten Verwandten in der Neuen Welt. Nach Tryon (1986) spricht man bei Farnen ab ca. 1000 km (600 Meilen) Distanz zwischen zwei Vorkommen von disjunkter Verbreitung; der Zwischenraum darf keine geeigneten Habitate enthalten. Im Fall von Afrika-Amerika-Disjunktionen ist dies eindeutig der Fall, da der Atlantik eine hinreichend breite Barriere darstellt. Auch besteht hier nicht die Möglichkeit, dass die Disjunktion sich durch Einbeziehung weiterer Spezies in die Untersuchung schließt.

Somit kann man für alle untersuchten südafrikanischen Arten bis auf Spezies 21-29 davon ausgehen, dass sie Teil disjunkter Gruppen sind. Da für den Clade aus Spezies 21-29 keine eindeutige Position in der Phylogenie gefunden wurde, ist die Disjunktion innerhalb des Clade aus Spezies 21-34 eher fraglich. Im MP-Ergebnis (Anhang Abb. 7.2) z. B. steht dieser Clade als Schwestergruppe des asiatischen Cheilanthes-Clade.

Givnish \& Renner (2004) nennen drei mögliche Erklärungen für Disjunktionen zwischen Afrika und Amerika: (1) eine ehemals kontinuierliche Verbreitung vor dem Auseinanderbrechen des Kontinents Gondwana, (2) eine Verbindung zwischen den Kontinenten durch eine zusammenhängende „boreotropische“ Flora der Nordhalbkugel während der thermalen Maxima im Alttertiär und (3) Langstreckenausbreitung über den Atlantik hinweg. Gondwana-Disjunktionen kommen innerhalb der Cheilanthoideae vermutlich nicht in Betracht. Schneider et al. 2004 datierten die Divergenz von Bommeria und Adiantum/Hecistopteris molekular auf 83,4 \pm 6,18 Millionen Jahre vor heute, also nach dem Auseinanderbrechen von Gondwana ca. 95 Millionen Jahre vor heute (Renner 2004). Bommeria ist die Außengruppe des vorliegenden Ergebnisses, die besprochenen Disjunktionen entstanden also (wahrscheinlich deutlich) nach dieser Divergenz (vgl. Abb. 3.1). Molekulare Datierungen sind allerdings stets mit Unsicherheiten behaftet, insbesondere wenn die zur Kalibrierung herangezogenen Divergenzen phylogenetisch weit von den zu datierenden Divergenzen entfernt sind.

Die Möglichkeit, dass zu Zeiten einer nordatlantischen Landbrücke eine kontinuierliche Verbreitung cheilanthoider Farne auf der Nordhalbkugel vorlag, müsste auf der Grundlage von paläoklimatologischen Daten diskutiert werden. Diese Möglichkeit scheint am ehesten für den Clade aus Spezies 21-29 in Frage zu kommen - sollte er mit den asiatischen Clade am nächsten verwandt sein (vgl. das MP-Ergebnis, Anhang Abb. 7.2) könnten gemeinsame Vorfahren eine nordhemisphärische Verbrei- 
tung gehabt haben. Die basale Position von Ch. pulchella (Kanarische Inseln) im asiatischen Clade legt nahe, dass diese Gruppe nicht über den Pazifik nach Asien gelangt ist (wie es vielleicht bei Paragymnopteris der Fall ist, vgl. Kirkpatrick 2007). Darüber hinaus gibt es aber keine Hinweise darauf, dass die Nordhalbkugel eine Rolle für den Ursprung der hier diskutierten Disjunktionen spielt. Langstreckenausbreitung von Sporen hingegen ist aus mehreren Gründen eine wahrscheinliche Erklärung. Farnsporen können durch Wind über weite Distanzen transportiert werden (Barrington 1993, Tryon 1986), wenngleich sie offenbar nicht ganz so gut flugfähig sind wie die Ausbreitungseinheiten von Moosen und Flechten (Muñoz et al. 2004). Eine einzelne Farnspore kann durch Selbstbefruchtung des Gametophyten eine neue Population gründen (ebd., Barrington 1993). Renner (2004) listet vier anemochore Blütenpflanzen-Gruppen mit Afrika-AmerikaDisjunktion (Ceiba pentandra, Maschalocephalos dinklagei, Pitcairnia feliciana, Melastomeae), für die eine Divergenzzeit-Untersuchung Langstreckenausbreitung als Ursache ergeben hat. Langstreckenausbreitung von Sporen ist also vor dem Hintergrund der verfügbaren Daten eine einfache und sinnvolle Erklärung für die Disjunktionen. Zu diesem Schluss kam auch Kirkpatrick (2007) bei einer entsprechenden Betrachtung von Disjunktionen im Verwandtschaftsbereich Pellaea/Paragymnopteris.

Weniger einfach ist die Interpretation der Ausbreitungsrichtung und der verantwortlichen Winde. Für $C h$. rawsonii und $P$. rufa liegt, gesetzt es hat Langstreckenausbreitung stattgefunden, eindeutig eine Ausbreitungsrichtung von Amerika nach Afrika vor. Nach Moran \& Smith (2001) stellen die südlich von $30^{\circ} S$ und nördlich von $30^{\circ} \mathrm{N}$ vorherrschenden Westwinde einen potentiellen Vektor dar (Moran \& Smith 2001). Pellaea rufa kommt tatsächlich in dieser Westwindzone vor, und auch für $C h$. rawsonii (ca. $28^{\circ} \mathrm{S}$ ) ist dieser Vektor noch denkbar. Die amerikanischen Schwesterspezies aus der vorliegenden Phylogenie kommen aber nur deutlich weiter nördlich vor. Wenn man aber annimmt, dass diese nicht die nächsten Verwandten sind, sondern vielleicht Ch. fraseri und P. myrtillifolia (Moran \& Smith 2001, s. o.), besteht kein derartiger Konflikt. Beide Spezies kommen bis in die Westwindzone vor. Renner (2004) hat gezeigt, dass der Transport von Früchten und Samen durch Meeresströmungen bei Blütenpflanzen der weitaus häufigere Mechanismus der Langstreckenausbreitung über den Atlantik ist. Die Idee, dass normalerweise windverbreitete Diasporen auch mit verdrifteten Pflanzenteilen den Ozean überqueren könnten (ebd.), ist vielleicht auch für Farnsporen bedenkenswert - es stellt sich allerdings die Frage, wie einmal gebundene Sporen wieder freigesetzt werden können, denn an der Meeresküste findet sich i. d. R. kein passendes Habitat. 
Innerhalb des Clade aus Spezies 1-56 (Abb. 3.2) sind wegen der phylogenetischen Unklarheiten Ausbreitungsrichtungen nicht feststellbar. Kirkpatrick (2007) konnte für diese Gruppe ebenfalls nicht entscheiden, ob sie ursprünglich alt- oder neuweltlich ist. Die Beobachtung von Moran \& Smith (2001) und Renner (2004), dass Langstreckenausbreitung per Wind gehäuft von Amerika nach Afrika stattgefunden hat, spricht für eine ursprünglich neuweltliche Verbreitung des Clade. Für die asymmetrische Ausbreitung windgetragener Diasporen gibt es allerdings noch keine konkrete Erklärung (Renner 2004). Die Windverhältnisse sind zwar offensichtlich asymmetrisch (ebd., Moran \& Smith 2001), die wirklich als Vektor fungierenden Windströmungen sind aber schwer zu identifizieren. Ein Ansatz ist der Vergleich floristischer Ähnlichkeiten mit Windrichtungen, den z. B. Moran \& Smith (2001) diskursiv verfolgten und für den Muñoz et al. (2004) eine quantitative Methode gefunden haben. Diese wurde auf die Floren zirkum-antarktischer Inseln sowie der Südspitzen von Afrika, Australien und Südamerika angewendet und ergab eine signifikante Korrelation von Windrichtung und floristischer Ähnlichkeit (ebd.). Um die Methode auf einer größeren Skala - wie z. B. für die Winde zwischen Afrika und Amerika - zu betreiben, müssten zunächst die entsprechenden Floren bzw. Checklisten windverbreiteter Arten vorliegen. Während z. B. für Flechten eine solche Datengrundlage existiert (Feuerer \& Hawksworth 2007), ist sie für Farne noch im Aufbau.

Speziation. Die Speziesgruppe 21-29 gehört komplett zum „southwestern endemic element" sensu Anthony (1984:279), hat ihren Verbreitungsschwerpunkt also im Westen und Südwesten des südlichen Afrika (Abb. 4.3). Alle beteiligten Arten sind endemisch in Südafrika und Namibia. Drei Arten (Cheilanthes robusta, Ch. deltoidea und Ch. kunzel) wurden dabei von Anthony unter „restricted endemism“ eingestuft. Wenn die heutige Verbreitung der beteiligten Arten nicht stark von der ursprünglichen abweicht, hat die durch den Clade repräsentierte Radiation im südwestlichen Afrika stattgefunden. Die Hypothese von Anthony (1984), dass „die südwestliche Ecke von Afrika" ein Zentrum der Speziation innerhalb der Cheilanthoideae war, wäre damit belegt.

Als Gegenhypothese ist denkbar, dass die Radiation in einem größeren Gebiet stattgefunden hat und die Areale später durch Veränderungen ökologischer (speziell: klimatischer) Faktoren zusammengedrängt wurden. Das südwestliche 


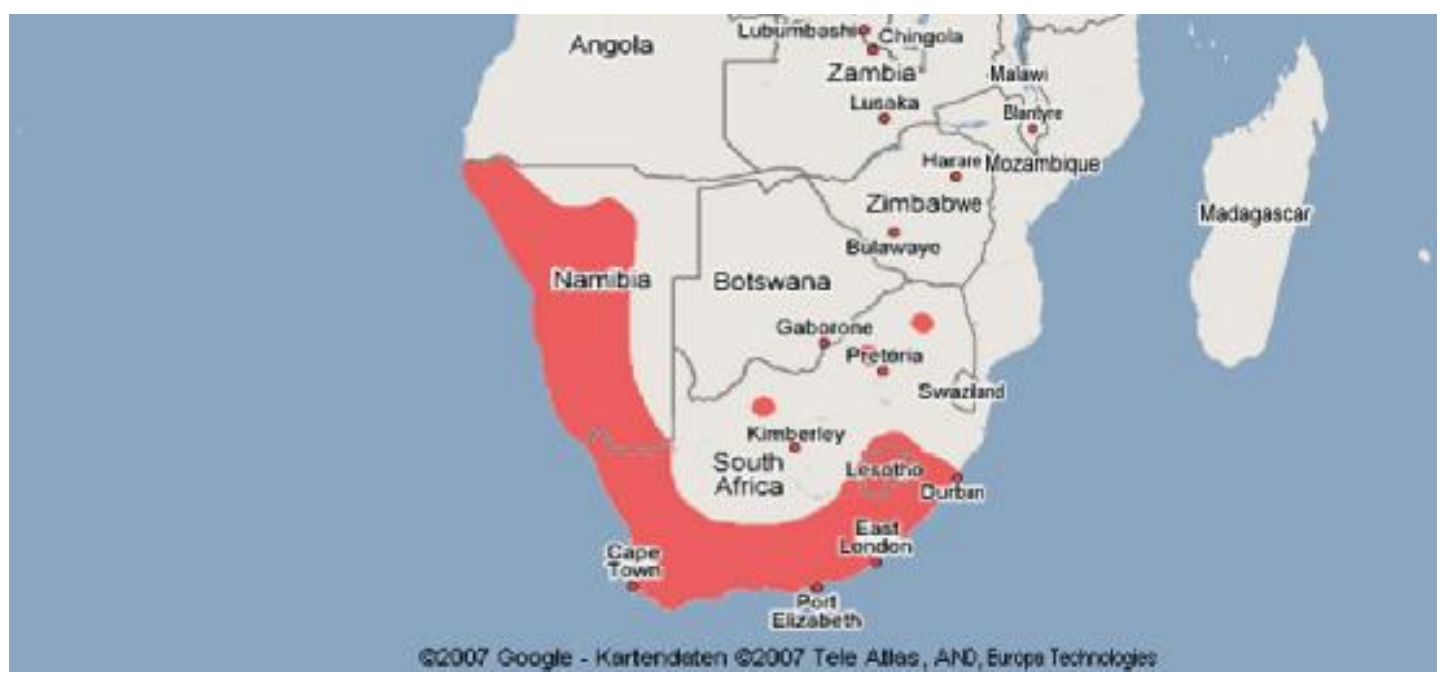

Abb. 4.3: Vereinigte Verbreitungsgebiete von Spezies 21-29 in Abb. 3.1: Cheilanthes capensis, Ch. deltoidea, Ch. hastata, Ch. kunzei, Ch. robusta, Ch. contracta, Ch. parviloba, Ch. marlothii und Ch. dinteri. (Eiserhardt 2007, Verbreitungsdaten aus Burrows 1990).

Afrika wäre dann für die Cheilanthoideae ein Refugium, kein Zentrum der Speziation. Ein Hinweis auf frühere größere Artareale findet sich bei Anthony selbst (1984:278): Drei Spezies (Ch. marlothii, Ch. parviloba und Ch. contracta, alle im hier diskutierten Clade enthalten) haben disjunkte Populationen im ehemaligen Transvaal, also außerhalb ihres eigentlichen Verbreitungsgebiets. Anthony formulierte die Möglichkeit, dass es sich dabei um Reliktpopulationen handelt. Das Verbreitungsmuster kann aber auch gut durch Ausbreitung erklärt werden. Die Entfernungen der disjunkten Populationen vom Hauptareal (Ch. marlothii: Maltahöhe [NAM] Gladysvale [Gauteng] 1100 km, Ch. parviloba: Nauchas [NAM] - De Doorns [Western Cape] 1150 km, Ch. contracta: Grahamstown [Eastern Cape] - Lydenburg [Mpumalanga] $1000 \mathrm{~km}$ ) sind nach Tryon (1986) für Farnsporen noch gut zu überwinden. Tryon (1986:135) spricht ab 1000 km überhaupt erst von disjunkten Populationen, erst ab $1600 \mathrm{~km}$ sei Ausbreitung selten. Berücksichtigt man noch, dass Vorkommen zwischen disjunkter Population und Hauptareal übersehen worden sein können, ist kein zwingender Grund gegeben, ehedem größere Artareale anzunehmen.

Gegen eine Refugialhypothese spricht zudem, dass es sich hier um eine große Zahl verwandter Spezies handelt. Für einen Relikt- bzw. Refugialendemismus wäre typisch, dass durch die klimatischen Veränderungen, die zu dieser Verbreitungsstruktur führen, die meisten Arten eines Verwandtschaftskreises aussterben. Typische Paläoendemiten haben keine oder wenige nahe Verwandte (Tryon 1986:134, Goldblatt 1997:364f.). Lokalendemiten, die über nahe Verwandte 
verfügen, sind nach Tryon (1986:134) „undoubtedly recent“. Das ist in diesem Fall eindeutig so. Die geringen Astlängen zwischen Cheilanthes contracta und Cheilanthes parviloba (Abb. 3.1) legen sogar nahe, dass diese beiden Spezies direkt aus einem Speziationsereignis hervorgegangen sind.

Die Tatsache, dass die Arten 21-29 weitgehend unter klimatischen Bedingungen vorkommen, die erst vor ca. 10-8 Millionen Jahren aufgekommen sein dürften (Linder \& Hardy 2004), spricht ebenfalls stark gegen eine Refugialhypothese. Nach Linder \& Hardy (2004:1623) hat bis in das Miozän (23-5,3 Millionen Jahre vor heute) in Südafrika ein tropisches oder subtropisches, nicht arides Sommerregen-Klima geherrscht. Das temperate Winterregengebiet, in dem ein großer Teil der Spezies (21-29) vorkommt, entstand demzufolge erst durch die vollständige Vereisung der Antarktis und die Formierung des kalten Benguela-Stroms entlang der südafrikanischen Atlantikküste.

Es gibt somit keinen Grund, für die cheilanthoiden Farne des südlichen Afrika eine Refugialverbreitung anzunehmen. Damit bleibt zur Erklärung des Clade (21-29) nur eine post-miozäne Lokalradiation, wie Anthony (1984) vermutet hat (Eiserhardt 2007).

Ein weiteres vermutlich südafrikanisches Speziationsereignis repräsentiert der Knoten zwischen Cheilanthes multifida subsp. multifida und Pellaea pteroides. Pellaea pteroides ist ein Fynbos-Endemit, und auch das Verbreitungsgebiet von $C h$. multifida subsp. multifida liegt im Wesentlichen im Winterregengebiet. Hier muss man analog annehmen, dass die Speziation zeitlich nach der Entstehung des Winterregen-Regimes stattgefunden hat. Auf eine größere Lokalradiation wie beim Clade aus Spezies 21-29 gibt es hier keine Hinweise.

Über die Auslöser und Mechanismen der Speziations-Ereignisse lässt sich auf Basis des vorliegenden Ergebnisses nichts sagen. Die verfügbaren Daten zur Ökologie der Arten (Anthony 1984, Burrows 1990) sind spärlich. Auch darf man nicht davon ausgehen, dass die hier gefundenen Speziespaare jeweils Abkömmlinge eines einzigen Divergenzereignisses sind. Am ehesten könnte man dies bei Ch. contracta und Ch. parviloba annehmen, die sehr geringe phylogenetische Astlängen zeigen (Abb. 3.1). Gerade bei diesen beiden Spezies fällt auf, dass ihr Verbreitungsgebiet (Abb. 4.4) in weiten Teilen „sympatrisch“ ist. Wegen der groben Auflösung der Verbreitungskarten (Burrows 1990) lässt sich aber nicht entscheiden, ob es sich um echte Sympatrie oder stark verschachtelte allopatrische Verbreitungsgebiete handelt. Im Falle echter Sympatrie wäre zu fragen, ob diese durch Areal-Verlagerungen im Nachgang zur Speziation (Tryon 1986:136) oder tatsächlich durch sympatrische Artbildung zustande gekommen ist. 
Zusammenfassend ergibt sich ein Bild von mindestens drei, wahrscheinlich vier Einwanderungsereignissen von cheilanthoiden Farnen ins südliche Afrika. Unabhängig vom Alter der Disjunktionen könnte Langstreckenausbreitung von Sporen aus Amerika die Ursache sein. Die Einbeziehung europäisch-mediterraner oder vorderasiatischer Arten ist notwendig, da diese im Falle einer Ausbreitung über die Nordhalbkugel Bindeglieder zwischen amerikanischen und afrikanischen Arten darstellen könnten. Ch. rawsonii und $P$. rufa dürften im Sinne von Tryon (1986) durch Artbildung im Anschluss an „Long-Distance Migration“ entstanden sein.

Der größere Teil der untersuchten Spezies scheint aber auf Speziation innerhalb der Region zurückzugehen. Eine quantitative Aussage über den Anteil von Einwanderung bzw. Iokaler Speziation an der heutigen Diversität der südafrikanischen Cheilanthoideae kann erst getroffen werden, wenn die Arten der Region zumindest mehrheitlich untersucht wurden.

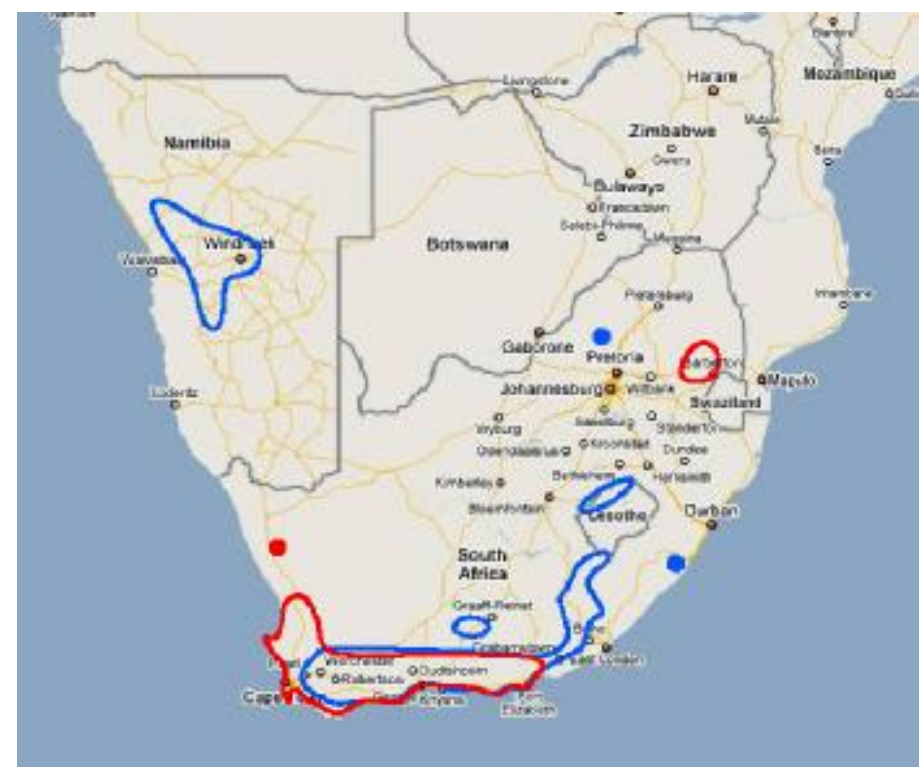

Abb. 4.4: Verbreitungsgebiete von Cheilanthes contracta (rot) und Ch. parviloba (blau). Kartenbasis: Google Maps, Verbreitungsdaten: Burrows (1990). 


\subsection{Fazit und Ausblick}

Eine überall gut unterstützte molekulare Phylogeniehypothese kann mit $r b c L$ allein nicht erreicht werden (vgl. Schuettpelz et al. 2007:1180).

Speziespaare und basale Verzweigungen (Clades 1-56, 1-59, 60-71) der erhaltenen Phylogenie zeigen eine gute Unterstützung, die dazwischen liegenden Divergenzereignisse sind weniger gut rekonstruierbar. Eine solche ungleichmäßige Verteilung kann darauf zurückzuführen sein, dass $r b c L$ als proteincodierendes Gen unterschiedliche Substitutionsraten in der ersten, zweiten und dritten Codon-Position hat (Yang 1996, Olmstead et al. 1998). Die drei Codon-Positionen können jeweils unterschiedliche Beiträge zum phylogenetischen Signal der Gesamtsequenz leisten (vgl. Hilu et al. 2003). Auch hängt die Substitutionsrate eines Codons von der Funktion der repräsentierten Aminosäure ab (Chase \& Albert 1998). Somit ist in zweifacher Hinsicht eine heterogene Verteilung von Substitutionsraten anzunehmen. Im hier untersuchten rbcL-Datensatz liegen nur 50 von 256 „Parsimony“-informativen Merkmalen auf Codon-Position 1 oder 2. Die betrachtete Phylogenie resultiert also größtenteils aus Codon-Position 3. Eine „Parsimony“-Analyse ausschließlich mit 3. Positionen hat eine beinahe genauso gut aufgelöste und unterstützte Phylogenie ergeben wie auf Basis der Gesamtsequenz. Auch die phylogenetisch tiefen Divergenzen zeigten dabei eine gute Unterstützung, die 3. Position ist also nicht mit Substitutionen übersättigt. Als mögliche Erklärungen für die beobachtete Ungleichverteilung der Auflösung bzw. Unterstützung bleiben a) eine nicht-gammaförmige Verteilung der Substitutionsraten zwischen den informativen Positionen und b) eine unterschiedliche Substitutions- oder Speziationsrate in verschiedenen Teilen der Phylogenie.

Um zu einer Phylogeniehypothese zu kommen, die in allen phylogenetischen Tiefen gut unterstützt ist, würde sich die Untersuchung mehrerer DNA-Regionen (MultiGen-Analyse) anbieten (wie bei Schuettpelz et al. 2007). Auch durch die Integration zusätzlicher Spezies/Sequenzen kann es zu einer Konsolidierung und Verfeinerung des Ergebnisses kommen (vgl. Gastony \& Rollo 1995:357).

Die vorliegenden Ergebnisse zeigen, dass die Cheilanthoideae des südlichen Afrika als geographisch umgrenzte Gruppe polyphyletisch sind; auf Basis nichtmolekularer Merkmale waren die verschiedenen Abstammungslinien nur in Einzelfällen (Ch. rawsonii, $P$. rufa) erkennbar. Um die molekulare Erfassung der Cheilanthoideae des südlichen Afrika auszuweiten, wurden vom Verfasser im September/Oktober 2007 bereits weitere Aufsammlungen in der Republik Südafrika getätigt. 


\section{Zusammenfassung/Abstract}

\subsection{Zusammenfassung}

Im Gegensatz zu den meisten Polypodiopsida kommen die cheilanthoiden Farne (Pteridaceae-Cheilanthoideae) mehrheitlich unter Bedingungen von saisonaler Austrocknung vor. Ihre Evolution muss demnach von Faktoren geprägt worden sein, die bei Farnen sonst nicht wirksam sind. Die Cheilanthoideae sind eine monophyletische Gruppe von ca. 300 Arten, in der Abstammungsgemeinschaften auf Basis morphologischer Merkmale kaum erkennbar sind. Als Hauptgrund für diese Schwierigkeit gilt konvergente Anpassung an Trockenheit. Molekularbiologische Untersuchungen (DNA-Sequenzen) ergaben aber für Teilgruppen gut aufgelöste und gut unterstützte Phylogeniehypothesen. Das südliche und südöstliche Afrika ist einer von sechs räumlich getrennten und bezüglich der vorkommenden Arten weitgehend disjunkten Diversitätsschwerpunkten der Cheilanthoideae. Arten aus dieser Region sind bislang kaum molekular untersucht worden. Aufgrund biogeographischer Untersuchungen wurde vermutet, dass der äußerste Südwesten Afrikas ein Zentrum der Speziation innerhalb der Cheilanthoideae darstellt. Ferner wurden auf Basis morphologischer Merkmale enge verwandtschaftliche Beziehungen zu neuweltlichen Spezies angenommen. Im Rahmen dieser Untersuchung wurden von 14 Arten aus dem südlichen Afrika (davon 11 bislang molekular ununtersucht) die Sequenzen des rbcL-Gens ermittelt und zusammen mit 64 Sequenzen aus der "GenBank“ phylogenetisch ausgewertet. Im Ergebnis bilden Cheilanthes capensis, Ch. deltoidea, Ch. hastata, Ch. kunzei, Ch. robusta, Ch. contracta, Ch. parviloba, Ch. marlothii und Ch. dinteri einen rein südafrikanischen Clade. Seine exakte Position in der Phylogenie ist nicht aufgelöst. Cheilanthes multifida ssp. multifida, Pellaea pteroides und $P$. calomelanos gruppieren basal in einem Clade mit Doryopteris sect. Doryopteris/Lytoneuron, Pellaea sect. Ormopteris, Trachypteris pinnata und zwei südamerikanischen Cheilanthes-Arten. Pellaea rufa bildet einen Clade mit Pellaea sect. Pellaea/Platyloma, Paragymnopteris, Astrolepis und Argyrochosma. Cheilanthes rawsonii gruppiert in einem Clade amerikanischer Cheilanthes-Arten. Alle Artengruppen und Spezies aus dem südlichen Afrika haben nach dieser Phylogenie ihre nächsten Verwandten in der Neuen Welt. Gesetzt eine ursprünglich neuweltliche Verbreitung der Unterfamilie, müssen mindestens dreimal Cheilanthoideae in das südliche Afrika eingewandert sein. Langstreckenausbreitung ist hierfür eine wahrscheinliche Erklärung. Der größere Teil der untersuchten 
Spezies aus dem südlichen Afrika scheint aber in dieser Region durch Speziation entstanden zu sein.

\subsection{Abstract}

Unlike most Polypodiopsida, cheilanthoid ferns (Pteridaceae-Cheilanthoideae) are adapted to seasonal draught. Their phylogeny must have been shaped by factors which are normally not active in ferns. Cheilanthoideae are a monophyletic group of about 300 species, among which evolutionary lineages are hard to infer from morphological characters. The main reason is said to be convergent adaptation to draught. However, molecular studies (DNA-sequences) yielded robust phylogenies for selections of Cheilanthoideae. Cheilanthoid ferns are concentrated in six geographically isolated regions with disjunctive species composition, of which southern and south-eastern Africa is one. Species from this region have been sparsely integrated in molecular studies. Based on non-molecular studies, the south-western corner of Africa has been proposed to be a centre of cheilanthoid fern speciation. Furthermore, close relations to New World species have been assumed. In this study, rbcL gene sequences have been determined for 14 southern African Cheilanthoid species, of which 11 have so far not been analyzed by means of DNA methods. A phylogeny was inferred from the new sequences together with $64 \mathrm{rbcL}$ sequences obtained from "GenBank". Cheilanthes capensis, Ch. deltoidea, Ch. hastata, Ch. kunzei, Ch. robusta, Ch. contracta, Ch. parviloba, Ch. marlothii and Ch dinteri form an exclusively southern African clade. The position of this clade is not resolved unequivocally. Cheilanthes multifida ssp. multifida, Pellaea pteroides and $P$. calomelanos nest basally in a clade of Doryopteris sect. Doryopteris/Lytoneuron, Pellaea sect. Ormopteris, Trachypteris pinnata and two southern American species of Cheilanthes. Pellaea rufa forms a clade together with Pellaea sect. Pellaea/Platyloma, Paragymnopteris, Astrolepis and Argyrochosma. Cheilanthes rawsonii nests in a clade of American species of Cheilanthes. According to this phylogeny, the closest relatives of all southern African species or species groups are of New World provenance. Given an ancestral New World distribution of Cheilanthoideae, Cheilanthoid Ferns must have immigrated into Africa at least three times. Long distance dispersal is a reasonable explanation. However, the main part of the analyzed southern African species apparently originates from speciation inside that region. 


\section{Literatur}

Aldasoro J. J., Cabezas F. \& Aedo C. (2004) Diversity and distribution of ferns in sub-Saharan Africa, Madagascar and some islands of the south Atlantic. - J. Biogeogr. 31(10), 1579-1604.

Anthony N. C. (1984) A revision of the southern African species of Cheilanthes Swartz and Pellaea Link (Pteridaceae). - Contr. Bolus Herb. 11, 2935.

Barrington D. S. (1993) Ecological and historical factors in fern biogeography. $-J$. Biogeogr. 20(3), 275-279.

Burrows J. E. (1990) Southern African Ferns and Fern Allies. - Frandsen Verlag, Sandton (RSA), 359S.

Chase M. W. \& Albert V. A. (1998) A Perspective on the Contribution of Plastid rbcL DNA Sequences to Angiosperm Phylogenies. - S. 488-507 in Soltis D. E., Soltis P. S. \& Doyle J. J. (Hrsg.) Molecular systematics of plants II. DNA Sequencing. Kluwer, Norwer, NY, 574 S.

Christ H. (1910) Die Geographie der Farne. - Gustav Fischer Verlag, Jena.

Eiserhardt, W. (2007) On the evolution of southern African cheilanthoid ferns (Pteridaceae subfam. Cheilanthoideae). - Poster Abstract: Botanikertagung Hamburg 2007.

Erixon P., Svennblad B., Britton T. \& Oxelman B. (2003) Reliability of Bayesian Posterior Probabilities and Bootstrap Frequencies in Phylogenetics. - Syst. Biol. 52(5), 665-673.

Felsenstein, J. (1985) Confidence limits on phylogenies: An approach using the bootstrap. - Evolution 39, 783-791.

Feuerer T. \& Hawksworth D. L. (2007) Biodiversity of lichens, including a world-wide analysis of checklist data based on Takhtajan's floristic regions. - Biodiversity Conservation 16(1) 85-98.

Gastony G. J. \& Rollo D. R. (1995) Phylogeny and generic circumscriptions of Cheilanthoid Ferns (Pteridaceae: Cheilanthoideae) inferred from rbcL nucleotide sequences. - Am. Fern J. 85(4), 341-360.

Gastony G. J. \& Rollo D. R. (1998) Cheilanthoid ferns (Pteridaceae: Cheilanthoideae) in the southwestern United States and adjacent Mexico - a molecular phylogenetic reassessment of generic lines. - Aliso 17(2), 131-144.

Gastony G. J. \& Yastkievych G. (2001) Morphological reassessment of molecular phylogenetic inferences in the xerically adapted cheilanthoid ferns (Pteridaceae: Cheilanthoideae). - Poster Abstract: Botany 2001, Albuquerque, New Mexico 12 16 August 2001.

Givnish T. J. \& Renner S. S. (2004) Tropical intercontinental disjunctions: Gondwana breakup, immigration from the Boreotropics, and transoceanic dispersal. - Int. J. Plant Sci. 165(S4), 1-6.

Goldblatt P. (1997) Floristic diversity in the Cape Flora of South Africa. - Biodiversity Conservation 6, 359-377.

Goldman N. \& Yang Z. (1994) A codon-based model of nucleotide substitution for protein-coding DNA sequences. - Mol. Biol. Evol. 11(5), 725-736. 
Hilu K. W., Borsch T., Müller K., Soltis D. E., Soltis P. S., Savolainen V., Chase M. W., Powell M. P., Alice L. A., Evans R., Sauquet H., Neinhuis C., Slotta T. A. B., Rohwer J. G., Campbell C. S. \& Chatrou L. W. (2003) Angiosperm Phylogeny based on matK Sequence Information. - Am. J. Bot. 90(12), 1758-1776.

Holder M. \& Lewis P. O. (2003) Phylogeny Estimation: Traditional and Bayesian Approaches. - Nature Reviews Genetics 4, 275-284.

Huelsenbeck J. P. \& Ronquist F. (2001) MRBAYES: Bayesian inference of phylogeny. - Bioinformatics 17, 754-755.

Kirkpatrick R. E. B. (2007) Investigating the monophyly of Pellaea (Pteridaceae) in the context of a phylogenetic analysis of cheilanthoid ferns. - Syst. Botany 32(3), 504-518.

Linder H. P. \& Hardy C. R. (2004) Evolution of the species-rich Cape flora. - Phil. Trans. R. Soc. Lond. B 359, 1623-1632.

Moran R. C. \& Smith A. R. (2001) Phytogeographic relationships between Neotropical and African-Madagascan Pteridophytes. - Brittonia 53(2), 304-351.

Muñoz J., Felicísimo Á. M., Cabezas F., Burgaz A. R. \& Martínez I. (2004) Wind as a Long-Distance Dispersal Vehicle in the Southern Hemisphere. - Science 304, 1144-1147.

Muse S. V. \& Gaut B. S. (1994) A Likelihood Approach for Comparing Synonymous and Nonsynonymous Substitution Rates, with Application to the Chloroplast Genome. - Mol. Biol. Evol. 11(5), 715-724.

Nakazato T. \& Gastony G. J. (2003) Molecular Phylogenetics of Anogramma Species and Related Genera (Pteridaceae: Taenitidoideae). - Syst. Botany 28(3), 490-502.

Olmstead R. G., Reeves P. A. \& Yen A. C. (1998) Choosing an Approach and an Appropriate Gene for Phylogenetic Analysis. - S. 164-187 in Soltis D. E., Soltis P. S. \& Doyle J. J. (Hrsg.) Molecular systematics of plants II. DNA Sequencing. Kluwer, Norwer, NY, 574 S.

Posada D. \& Crandall K. A. (1998) Modeltest: testing the model of DNA substitution. - Bioinformatics 14(9), 817-818.

Prado J., Del Nero Rodrigues C., Salatino A. \& Salatino M. L. F. (2007) Phylogenetic relationships among Pteridaceae, including Brazilian species, inferred from $r b c L$ sequences. - Taxon 56(2), 355-368.

Pryer K. M., Schuettpelz E., Wolf P. G., Schneider H., Smith A. R. \& Cranfill R. (2004) Phylogeny and evolution of Ferns (Monilophytes) with a focus on the early Leptosporangiate divergences. - Am. J. Bot. 91(10), 1582-1598.

Renner S. S. (2004) Plant dispersal across the tropical Atlantic by wind and sea currents. - Int. J. Plant Sci. 165(S4), 23-33.

Rohwer J. G. \& Rudolph B. (unpub.) Molekulare Methoden der Systematik und Populationsanalyse. $-31 \mathrm{~S}$.

Ronquist F. \& Huelsenbeck J. P. (2003) MRBAYES 3: Bayesian phylogenetic inference under mixed models. - Bioinformatics 19, 1572-1574.

Ronquist F., Huelsenbeck J. P. \& van der Mark P. (2005) MrBayes 3.1 Manual. Draft 5/26/2005. - http://mrbayes.scs.fsu.edu/.

Sambrook J. \& Russell D. W. (2001) Molecular cloning. A laboratory manual. Third edition. Cold Spring Harbor, New York. 
Schneider H., Schuettpelz E., Pryer K. M., Cranfill R., Magallón S. \& Lupia R. (2004) Ferns Diversified in the Shadow of Angiosperms. - Nature 428, 553-557.

Schuettpelz E., Schneider H., Huiet L., Windham M. D., Pryer K. M. (2007) A molecular phylogeny of the fern family Pteridaceae: Assessing overall relationships and the affinities of previously unsampled genera. - Mol. Phylogenet. Evol. 44, 1172-1185.

Smith A. R., Pryer K. M., Schuettpelz E., Korall P., Schneider H. \& Wolf P. G. (2006) A classification for extant ferns. - Taxon 55(3), 705-731.

Swofford D. L. (2003) PAUP*. Phylogenetic Analysis Using Parsimony ("and Other Methods). Version 4. Sinauer Associates, Sunderland, Massachusetts.

Tryon R. \& Tryon A. F. (1973) Geography, spores and evolutionary relations in the cheilanthoid ferns. - S. 145-153 in Jermy A. C., Crabbe J. A. \& Thomas B. A. (Hrsg.) The phylogeny and classification of the ferns. Bot. J. Linn. Soc. 67 (S1).

Tryon R. \& Tryon A. F. (1982) Ferns and allied plants with special reference to tropical America. Springer Verlag, New York, 857S.

Tryon R. (1986) The Biogeography of Species, with Special Reference to Ferns. The Botanical Review 52, 117-156.

Tryon R., Tryon A. F. \& Kramer K. U. (1990) Pteridaceae. - S. 230-256 in: Kubitzki K. (Hrsg.) The families and genera of vascular plants, Bd. 1, Pteridophytes and gymnosperms, Kramer K. U. \& Green P. S. (Bd. Hrsg.). Springer Verlag, New York.

Windham M. D. \& Rabe W. E. (1993) Cheilanthes. - S. 152-169 in Flora of North America Editorial Committee (Hrsg.) Flora of North America north of Mexico, Bd. 2, Pteridophytes and gymnosperms. Oxford University Press, New York, 475S.

Yang Z. (1996) Among-site rate variation and its impact on phylogenetic analyses. TREE 11(9), 367-372.

Zhang G., Zhang X. \& Chen Z. (2005) Phylogeny of cryptogrammoid ferns and related taxa based on rbcL sequences. - Nord. J. Bot. 23, 485-493.

Zhang G., Zhang X., Chen Z., Liu H. \& Yang W. (2007) First insights in the phylogeny of Asian cheilanthoid ferns based on sequences of two chloroplast markers. - Taxon 56(2), 369-378.

Zuccon A. \& Zuccon D. (2006) MrEnt v1.2. Programme distributed by the authors. Department of Vertebrate Zoology \& Molecular Systematics Laboratory, Swedish Museum of Natural History, Stockholm.

Zwickl D. J. (2006) Genetic algorithm approaches for the phylogenetic analysis of large biological sequence datasets under the maximum likelihood criterion. Ph.D. dissertation, The University of Texas at Austin. 


\section{Anhang}

Tab. 7.1: Herkunft, geographische Koordinaten und Belegnummern der Aufsammlungen, von denen für die vorliegende Untersuchung $r b c L-S e q u e n z e n$ angefertigt wurden. $Z A=$ Republik Südafrika, SWA=Namibia, WC=Western Cape, NC=Northern Cape, E=Spanien.

\begin{tabular}{|c|c|c|c|c|}
\hline Spezies & Herkunft & Länge & Breite & Belegnr. \\
\hline Cheilanthes capensis (Thunb.) Swartz & $\begin{array}{l}\text { Paarl, } \\
\text { WC, ZA }\end{array}$ & $-33,71906172$ & 18,95126891 & WE-062d \\
\hline Ch. contracta (Kunze) Mett. ex Kuhn & $\begin{array}{l}\text { Paarl, } \\
\text { WC, ZA }\end{array}$ & $-33,73725934$ & 18,94332429 & WE-065 \\
\hline Ch. deltoidea Kunze & $\begin{array}{l}\text { Umdaus, } \\
\text { NC, ZA }\end{array}$ & $-29,07331000$ & 17,64793251 & 127.270 \\
\hline Ch. dinteri Brause & $\begin{array}{l}\text { Fyndraai, } \\
\text { SWA }\end{array}$ & $-23,18190345$ & 16,87259764 & Fyndraai 1 \\
\hline Ch. hastata (L. f.) Kunze & $\begin{array}{l}\text { Paarl, } \\
\text { WC, ZA }\end{array}$ & $-33,72264541$ & 18,94938475 & WE-063 \\
\hline Ch. cf. kunzei Mett. & $\begin{array}{l}\text { Richtersveld, } \\
\text { NC, ZA }\end{array}$ & $-28,76315989$ & 17,15261517 & 127.273 \\
\hline Ch. marlothii (Hieron.) Schelpe & $\begin{array}{l}\text { Fyndraai, } \\
\text { SWA }\end{array}$ & $-23,18190345$ & 16,87259764 & Fyndraai2 \\
\hline Ch. multifida (Swartz) Swartz & $\begin{array}{l}\text { Paarl, } \\
\text { WC, ZA }\end{array}$ & $-33,73704300$ & 18,94066949 & WE-064 \\
\hline Ch. parviloba (Swartz) Swartz & $\begin{array}{l}\text { Prince Albert, } \\
\text { SC, ZA }\end{array}$ & $-33^{\circ} 13^{\prime} 55.4^{\prime \prime S}$ & $22^{\circ} 01^{\prime} 48.4^{\prime \prime} \mathrm{E}$ & Roux4163 \\
\hline Ch. rawsonii (Pappe) Mett. ex Kuhn & $\begin{array}{l}\text { Richtersveld, } \\
\text { NC, ZA }\end{array}$ & $-28,27700892$ & 17,04333770 & 127.477 \\
\hline Ch. robusta (Kunze) Tryon & $\begin{array}{l}\text { Richtersveld, } \\
\text { NC, ZA }\end{array}$ & $-28,35889726$ & 16,99289306 & 127.478 \\
\hline Pellaea calomelanos Swartz (Link) & $\begin{array}{l}\text { Fyndraai, } \\
\text { SWA }\end{array}$ & $-23,18190345$ & 16,87259764 & Fyndraai3 \\
\hline P. pteridoides (L.) Prantl & $\begin{array}{l}\text { Paarl, } \\
\text { WC, ZA }\end{array}$ & $-33,71906172$ & 18,95126891 & WE-062a \\
\hline P. rufa A. Tryon & $\begin{array}{l}\text { Laingsburg, } \\
\text { SC, ZA }\end{array}$ & $-33^{\circ} 09^{\prime} 30.7^{\prime \prime S}$ & $20^{\circ} 52 ' 27.1 " \mathrm{E}$ & Roux4202 \\
\hline Cheilanthes pulchella Bory ex Willd. & $\begin{array}{l}\text { Guïmar, } \\
\text { Teneriffa, E }\end{array}$ & & & \\
\hline
\end{tabular}


Abb. 7.1: Herkunft der

Aufsammlungen, von denen für die

vorliegende Untersuchung rbcL-

Sequenzen angefertigt wurden. Die

Benennung folgt den Belegnummern (vgl. Tab. 7.1).

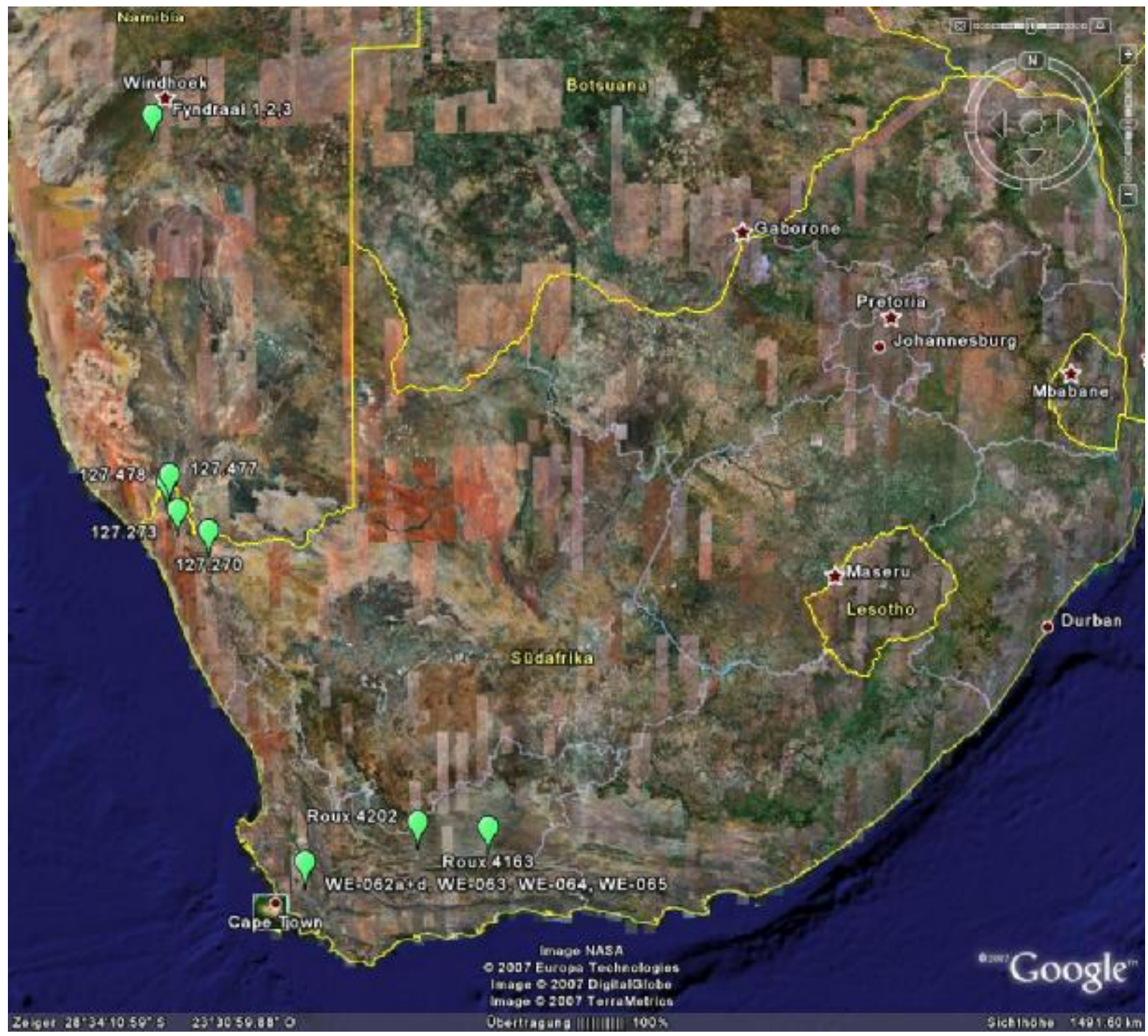


Tab. 7.2: Über die "GenBank" (www.ncbi.nlm.nih.gov/) bezogene Sequenzen aus früheren Untersuchungen: [1] Hasebe et al. (1994), [2] Gastony \& Johnson (2001), [3] Gastony \& Rollo (1995), [4] Zhang et al. (2005), [5] Prado et al. (2007), [6] Zhang,G. (2007), [7] Geiger,J.M.O. and Ranker,T.A. (unpub.). ${ }^{*}=$ keine Angabe zur Aufsammlung verfügbar, Verbreitung aus der Datenbank des Missouri Botanical Garden (http://www.mobot.org/).

\begin{tabular}{|c|c|c|c|}
\hline Art & $\begin{array}{l}\frac{c}{d} \\
\frac{0}{0} \\
\frac{7}{3}\end{array}$ & Herkunft & gi-Nummer \\
\hline Aleuritopteris albomarginata (C.B.Clarke) Ching & {$[4]$} & Indien, Simla & 32967501 \\
\hline A. argentea (Gmél.) Fée & {$[4]$} & China, Beijing, Mt. Dongling & 32967499 \\
\hline A. duclouxii (H.Christ) Ching & [3] & China, Yunnan & 882423 \\
\hline A. formosana (Hayata) Tagawa & {$[6]$} & Indien, Simla & 90193641 \\
\hline A. grisea (Blanford) Panigrahi & {$[4]$} & China, Yunnan, Zhongdian & 34329201 \\
\hline A. likiangensis Ching & {$[6]$} & China, Sichuan, Muli & 90193645 \\
\hline A. niphobola (C.Chr.) Ching & {$[4]$} & China, Sichuan, Kangding & 32967497 \\
\hline A. squamosa (Hope \& C.H.Wright) & {$[6]$} & China, Hainan, Bawangling & 90193639 \\
\hline A. tamburii (Hook.) Ching & {$[6]$} & China, Yunnan, Lijiang & 90193643 \\
\hline Aspidotis californica (Hook.) Nutt. ex Copel. & {$[2]$} & USA, California & 21628856 \\
\hline Bommeria ehrenbergiana (Klotzsch) Underw. & [3] & Mexico, Hidalgo & 885866 \\
\hline Cheilanthes albofusca Baker & [3] & China, Yunnan & 885868 \\
\hline Ch. allosuroides Mett. & [3] & Mexico, Jalisco & 882419 \\
\hline Ch. aurea Baker & {$[3]$} & Mexico, Oaxaca & 886822 \\
\hline Ch. bonariensis (Willd.) Proctor & [3] & Mexico, Michoacan & 885870 \\
\hline Ch. chinensis (Baker) Domin & {$[6]$} & China, Chongqing, Nanchuan & 90193657 \\
\hline Ch. decora (Brack.) R.\&A.Tryon & [3] & Hawaii, Kaui & 882421 \\
\hline Ch. flexuosa Kunze & {$[5]$} & Brasilien, Minas Gerais & 134303575 \\
\hline Ch. goyazensis (Taub.) Domin & {$[5]$} & Brasilien, Minas Gerais & 134303577 \\
\hline Ch. horridula Maxon & [3] & Mexico, Nuevo León & 882425 \\
\hline $\begin{array}{l}\text { Ch. intramarginalis (Kaulf. ex Link) Hook. var. } \\
\text { serratifolia (Hook. \& Baker) C.C.Hall \& Lell. }\end{array}$ & [3] & Mexico, Hidalgo & 882427 \\
\hline Ch. lanosa (Michx.) D.C.Eaton & [3] & USA, Indiana, Martin Co. & 882415 \\
\hline Ch. rigida (Sw.) Mett. & [3] & Mexico, Puebla & 886828 \\
\hline Cheilosoria insignis (Ching) Ching et K.H.Shing & {$[4]$} & China, Xizang, Gyaca & 32967505 \\
\hline Ch. patula (Baker) P.S.Wang & {$[6]$} & China, Chongqing, Nanchuan & 90193637 \\
\hline Doryopteris collina (Raddi.) J.Sm. & {$[5]$} & Brasilien, Minas Gerais & 134303579 \\
\hline D. concolor (Langsd. \& Fisch.) Kuhn & {$[1]$} & Taiwan, Nantoh & 511548 \\
\hline D. lomariacea Klotzsch & {$[5]$} & Brasilien, Campos de Jordão & 134303581 \\
\hline D. nobilis (T.Moore) C.Chr. & {$[5]$} & Brasilien, Rio de Janeiro & 134303583 \\
\hline D. ornithopus (Hook. \& Baker) J.Sm. & {$[5]$} & Brasilien, Minas Gerais & 134303585 \\
\hline D. paradoxa (Fée) Christ. & {$[5]$} & Brasilien, Rio de Janeiro & 134303587 \\
\hline D. pedata (L.) Fée var. palmate (Willd.) Hicken & [3] & Mexico, Hidalgo & 882417 \\
\hline D. pentagona Pic. Serm. & {$[5]$} & Brasilien, Rio de Janeiro & 134303589 \\
\hline D. rediviva Fée & {$[5]$} & Brasilien, Rio de Janeiro & 134303591 \\
\hline D. sagittifolia (Raddi) J. Sm. & {$[5]$} & Brasilien, Rio de Janeiro & 134303593 \\
\hline H. levyi Fourn. & [3] & Mexico, Oaxaca & 886753 \\
\hline
\end{tabular}




\begin{tabular}{|c|c|c|c|}
\hline H. palmata L. & [7] & Mittel- und Südamerika* & 34014844 \\
\hline H. rufa (L.) Sw. & [7] & Mittel- und Südamerika* & 34014842 \\
\hline H. tomentosa (Lam.) Raddi & [7] & Südamerika* & 34014846 \\
\hline $\begin{array}{l}\text { Leptolepidium dalhousiae } \\
\text { (Hook.) K.H.Shing \& S.K.Wu }\end{array}$ & {$[6]$} & China, Yunnan, Zhongdian & 90193647 \\
\hline L. kuhnii (Milde) K.H.Shing et S.K.Wu & {$[4]$} & $\begin{array}{l}\text { China, Beijing, } \\
\text { Mt. Donglingshan }\end{array}$ & 32967503 \\
\hline Mildella nitidula (Wall. ex Hook.) Hall \& Lellinger & {$[6]$} & China, Sichuan, Kangding & 90193631 \\
\hline M. paupercula (H.Christ) Hall \& Lellinger & {$[6]$} & China, Sichuan, Luding & 90193635 \\
\hline Notholaena delicatula Maxon \& Weath. & [3] & Mexico, Nuevo León & 885872 \\
\hline N. fendleri Kunze & [3] & $\begin{array}{l}\text { USA, New Mexico, } \\
\text { Sandoval Co. }\end{array}$ & 886757 \\
\hline N. rosei Maxon & [3] & Mexico, Oaxaca & 886759 \\
\hline N. sulphurea (Cav.) J.Sm. & [3] & Mexico, Puebla & 886804 \\
\hline Paragymnopteris bipinnata (H.Christ) K.H. Shing & {$[6]$} & China, Yunnan, Zhongdian & 90193667 \\
\hline P. delavayi (Baker) K.H.Shing & {$[6]$} & China, Sichuan, Kangding & 90193663 \\
\hline P. marantae (L.) K.H.Shing & {$[6]$} & China, Yunnan, Zhongdian & 90193665 \\
\hline P. sargentii (H.Christ) K.H.Shing & {$[6]$} & China, Yunnan, Deqin & 90193661 \\
\hline P. vestita (Wall. ex Presl) K.H.Shing & {$[6]$} & China, Yunnan, Kunming & 90193659 \\
\hline Pellaea andromedifolia (Kaulf.) Fée & [3] & USA, California, Orange Co. & 885874 \\
\hline P. boivinii Hook. & [3] & $\begin{array}{l}\text { Madagascar, } \\
\text { Prov. Fianarantsoa }\end{array}$ & 886830 \\
\hline P. cordifolia (Sessé \& Moc.) A.R.Smith & [3] & USA, Texas, Jeff Davis Co. & 886806 \\
\hline P. cymbiformis J.Prado & {$[5]$} & Brasilien, Minas Gerais & 134303597 \\
\hline P. gleichenioides (Hook.) Christ & [5] & Brasilien, Minas Gerais & 134303599 \\
\hline P. pinnata (Kaulf.) Prantl & {$[5]$} & Brasilien, Minas Gerais & 13430360 \\
\hline P. pringlei Davenp. & {$[3]$} & Mexico, Morelos & 886824 \\
\hline P. riedelii Baker & {$[5]$} & Brasilien, Minas Gerais & 134303603 \\
\hline P. rotundifolia (G.Forst) Hook. & {$[3]$} & (Indiana Univ. Greenhouse) & 886826 \\
\hline Sinopteris albofusca (Baker) Ching & {$[6]$} & China, Sichuan, Kangding & 90193649 \\
\hline S. grevilleoides (H.Christ) C.Chr. \& Ching & {$[6]$} & China, Yunnan, Dayao & 90193651 \\
\hline Trachypteris pinnata (Hook. f.) C.Chr. & [3] & Bolivia, Prov. Santa Cruz & 882429 \\
\hline
\end{tabular}


Tab. 7.3: Verwendete Chemikalien, „Kits“ und Lösungen.

\section{Chemikalien/“Kits“ alphabetisch}

1 kb DNA Ladder

ABI PRISMTM Bigdy Ready Reaction Kit

\section{Agarose}

Borsäure

Bromphenolblau

Ethanol $99.8 \%$

Ethidiumbromid

Glycerin

Invisorb® Spin Plant Mini Kit

Millipore Montage PCR Device

Natriumacetat

$\mathrm{Na}_{2}$ EDTA, Titriplex® III

Oligonukleotide

PuReTaq Ready-To-Go PCR Beads

Silica Gel Orange

Tris $\mathrm{HCl}$ (Tris-Hydrochlorid)

Wasser ROTISOLV® HPLC Gradient Grade

\section{Bezugsquelle}

GeneCraft GmbH Münster

\section{Lösungen:}

5x TBE-Puffer, pH 8,4 (Sambrook \& Russel, 2001)

Tris $890 \mathrm{mM}$

Borsäure $890 \mathrm{mM}$

EDTA $20 \mathrm{mM}$

BPB+Glyc. (Ladepuffer)

$30 \%$ Glycerin (vol./vol.)

0,25\% Bromphenolblau (weight/vol.)

Ethidiumbromidbad

$75 \mu \mathrm{l}$ Ethidiumbromid-Stammlösung $(10 \mathrm{mg} / \mathrm{ml})$ in $250 \mathrm{ml} \mathrm{H} 2 \mathrm{O}$ bidest. 
Tab. 7.4: Für die „Polymerase Chain Reaction“ und die Sequenzierreaktion verwendete Oligonukleotide („Primer“).

\begin{tabular}{lll} 
Name & $\mathbf{5}^{\prime}$ - Sequenz - 3' & Quelle \\
\hline 1F & ATG TCA CCA CAA ACA GAA ACT AAA GCA AGT & www.pryerlab.net \\
M34 & GGA TTT AAA GCT GGT GT & www.pryerlab.net \\
440F & GGT AAT GTT TTT GGA TTT AAG GC & Gastony \& Rollo (1995) \\
$645 F$ & CYC AAC CAW YTA TGC GTT GGA G & www.pryerlab.net \\
$636 \mathrm{R}$ & AAT AAG AAA CGA TCY CTC CAA CG & www.pryerlab.net \\
888R & TGT CTR TCR ATA ACA GCA TGC AT & www.pryerlab.net \\
1351R & CTT CAC AAG CAG CAG CTA GTT CAG GAC TCC & Gastony \& Rollo (1995)
\end{tabular}




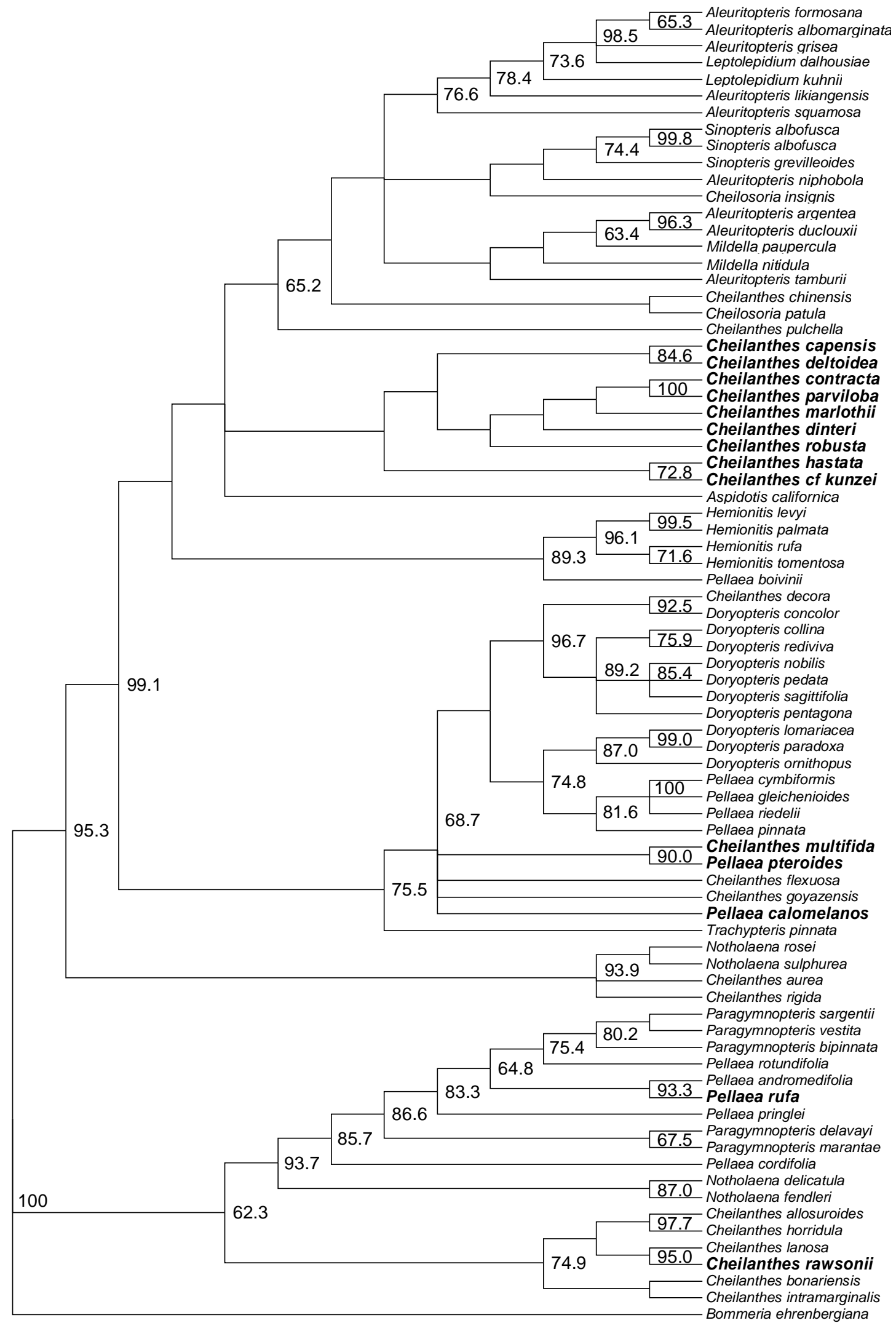

Abb. 7.2: „Strict Consensus“ von 96 sparsamsten Topologien aus 79 rbcL-Sequenzen cheilanthoider Farne. Zahlen an den Knoten sind „Maximum Parsimony Bootstrap“-Werte $\geq 60$. Fettgedruckt: Arten aus dem südlichen Afrika. 


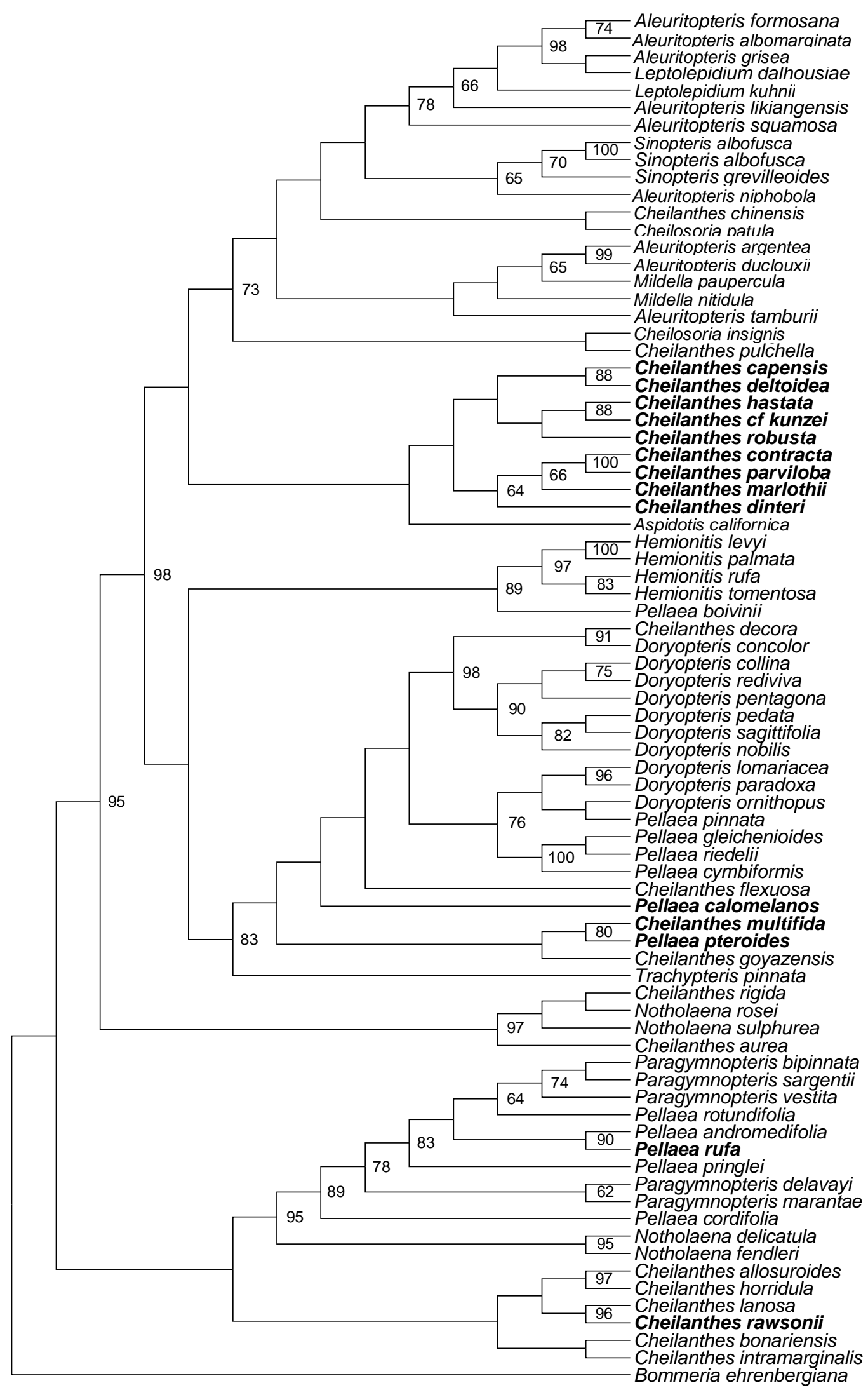

Abb. 7.3: „Majority Rule Consensus“ von 100 "Maximum Likelihood Bootstrap”-Pseudoreplikaten (GTR+I+ $\Gamma$, Parameter in GARLI ermittelt) auf Basis von 79 rbcL-Sequenzen cheilanthoider Farne. Fettgedruckt: Arten aus dem südlichen Afrika. 


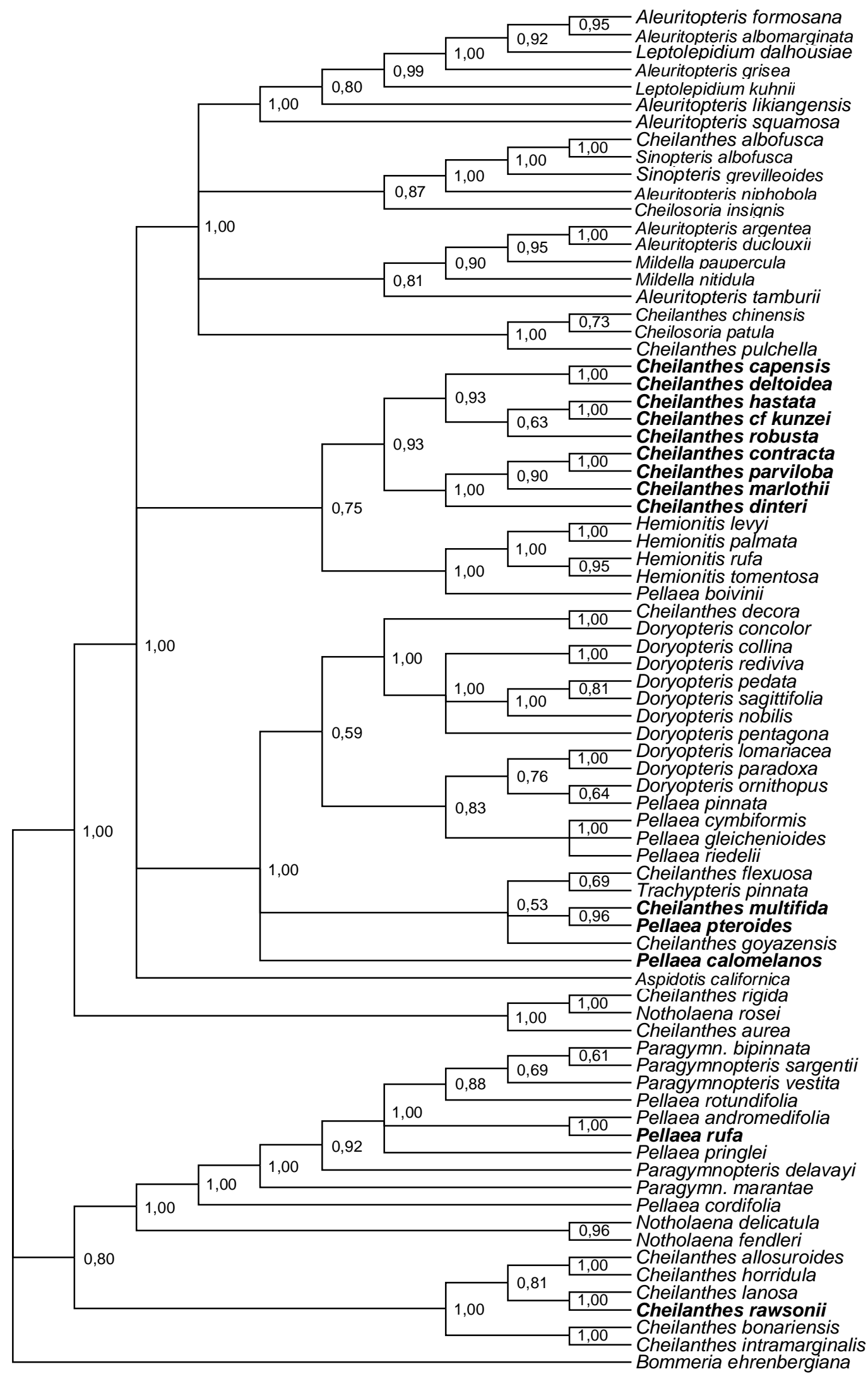

Abb. 7.4: „Majority Rule Consensus“ einer „Bayesian Inference of Phylogeny” (Codon-Modell, GTR $+\mathrm{I}+\Gamma, 25 \%$ "Burnin") auf Basis von $78 \mathrm{rbcL}-$ Sequenzen cheilanthoider Farne. Die Zahlen an den Knoten sind „Bayesian Posterior Probability“-Werte. Fettgedruckt: Arten aus dem südlichen Afrika. 


\section{Dank}

Ich danke Professor Dr. Jens G. Rohwer und Dr. Tassilo Feuerer für die Betreuung, die ich mir besser nicht hätte wünschen können. Dr. Harald Schneider (NHM, London) danke ich herzlich für sein Interesse an meiner Arbeit und für viele fachlich wertvolle Gespräche. Professor Dr. Norbert Jürgens bin ich außerordentlich dankbar für die Unterstützung meiner Sammeltätigkeit in Südafrika, nicht zuletzt durch die Möglichkeit, an zwei Projektreisen im Rahmen von BIOTA Southern Africa teilnehmen zu dürfen. Dr. Barbara Rudolph führte mich sachkundig in die Laborarbeit ein und war stets bereit, mir bei der Lösung von Problemen zu helfen, dafür bin ich ihr sehr dankbar. Ich danke Dr. Koos Roux (Compton Herbarium, Kapstadt) für die Bereitstellung von Material und für wertvolle Hinweise, Dr. Matthias Schultz und Dirk Wesuls für die Bereitstellung von Material, Tracy Seaman (UCT, Kapstadt) für ihre unschätzbare Hilfe beim Sammeln im Western Cape, Cape Nature für die Sammelgenehmigungen AAA005-00058-0028 und AAA005-00086-0028 und Eric Philander für die unkomplizierte Interaktion mit Cape Nature. Andrea Jounais und Anna Maria Vogt danke ich für das perfekte Labor und ihre Unterstützung bei der Nutzung desselben. Mein weiterer Dank gilt Dr. Klaus H. Eiserhardt und Sabrina Schmidt für Kommentare zum Manuskript, Dorothea Eiserhardt für Kommentare zur englischen Zusammenfassung und Cyrille Claudel für viele hilfreiche Hinweise. Bei Elke Erb, Sven Dorendorf, Sabine Greiner, Wiebke Hanke, Jannis Liedtke, Imke Oncken, Anna de la Roca, Inga Röwer und Simon Thomsen bedanke ich mich für das Ausschau halten nach Farnen während der gemeinsamen Zeit im Gelände. 


\section{Urheberschaftserklärung}

Ich versichere, dass ich die Arbeit ohne fremde Hilfe verfasst und mich dabei anderer als der angegebenen Hilfsmittel nicht bedient habe.

Ich bin mit einer späteren Ausleihe der Arbeit einverstanden.

19.12.2007 Wolf L. Eiserhardt 